\title{
Neuroprotection and Acute Spinal Cord Injury: A Reappraisal
}

\author{
Edward D. Hall and Joe E. Springer \\ Spinal Cord and Brain Injury Research Center, University of Kentucky Chandler Medical Center, Lexington, Kentucky 40536
}

\begin{abstract}
Summary: It has long been recognized that much of the posttraumatic degeneration of the spinal cord following injury is caused by a multi-factorial secondary injury process that occurs during the first minutes, hours, and days after spinal cord injury (SCI). A key biochemical event in that process is reactive oxygeninduced lipid peroxidation (LP). In 1990 the results of the Second National Acute Spinal Cord Injury Study (NASCIS II) were published, which showed that the administration of a high-dose regimen of the glucocorticoid steroid methylprednisolone (MP), which had been previously shown to inhibit post-traumatic LP in animal models of SCI, could improve neurological recovery in spinal-cord-injured humans. This resulted in the registration of high-dose MP for acute SCI in several countries, although not in the U.S. Nevertheless, this treatment quickly became the standard of care for acute SCI since the drug was already on the U.S. market for many other indications. Subsequently, it was demonstrated that the non-glucocorticoid 21-aminosteroid tirilazad could duplicate the antioxidant neuroprotective efficacy of MP in SCI models, and evidence of human efficacy was obtained in a third NASCIS trial (NASCIS III). In recent years,
\end{abstract}

the use of high-dose MP in acute SCI has become controversial largely on the basis of the risk of serious adverse effects versus what is perceived to be on average a modest neurological benefit. The opiate receptor antagonist naloxone was also tested in NASCIS II based upon the demonstration of its beneficial effects in SCI models. Although it did not a significant overall effect, some evidence of efficacy was seen in incomplete (i.e., paretic) patients. The monosialoganglioside GM1 has also been examined in a recently completed clinical trial in which the patients first received high-dose MP treatment. However, GM1 failed to show any evidence of a significant enhancement in the extent of neurological recovery over the level afforded by MP therapy alone. The present paper reviews the past development of MP, naloxone, tirilazad, and GM1 for acute SCI, the ongoing MP-SCI controversy, identifies the regulatory complications involved in future SCI drug development, and suggests some promising neuroprotective approaches that could either replace or be used in combination with high-dose MP. Key Words: Spinal cord injury, secondary injury, neuroprotection, methylprednisolone, naloxone, apoptosis.

\section{INTRODUCTION}

Although spinal cord injury (SCI) can victimize active individuals at any age, most occur in young adults in the second and third decades of life. Those who survive their initial injuries can now expect to live long lives because of improvements in medical and surgical care, although intensive rehabilitation and prolonged disability exacts a significant toll on the individual, his or her family, and society. Effective ways of maintaining or recovering function could markedly improve the outlook for those with traumatic SCI by enabling higher levels of independence and productivity.

The potential for pharmacological intervention to either preserve or recover neurological function after SCI exists due to the fact that most traumatic injuries do not involve actual physical transection of the cord, but rather the spinal cord is damaged as a result of a contusive,

Address correspondence and reprint requests to Edward D. Hall, Ph.D., 800 Rose Street, 232 Health Sciences Research Building, Lexington, KY 40536-0305. E-mail: edhall@uky.edu. compressive, or stretch injury. Typically, residual white matter containing portions of the ascending sensory and descending motor tracts remains intact, allowing for the possibility of neurological recovery. However, during the first minutes and hours following injury, a secondary degenerative process is initiated by the primary mechanical injury that is proportional to the magnitude of the initial insult. Nevertheless, the initial anatomical continuity of the injured spinal cord in the majority of cases, together with our present knowledge of many of the factors involved in the secondary injury process, has lead to the notion that pharmacological treatments which interrupt the secondary cascade, if applied early, could improve spinal cord tissue survival, and thus preserve the necessary anatomic substrate for functional recovery to take place.

\section{PRINCIPAL MECHANISMS OF SECONDARY SCI}

Several reviews of post-SCI secondary injury have been published. ${ }^{1-6}$ FIG. 1 graphically outlines many of the key players and the complex interrelationships in- 


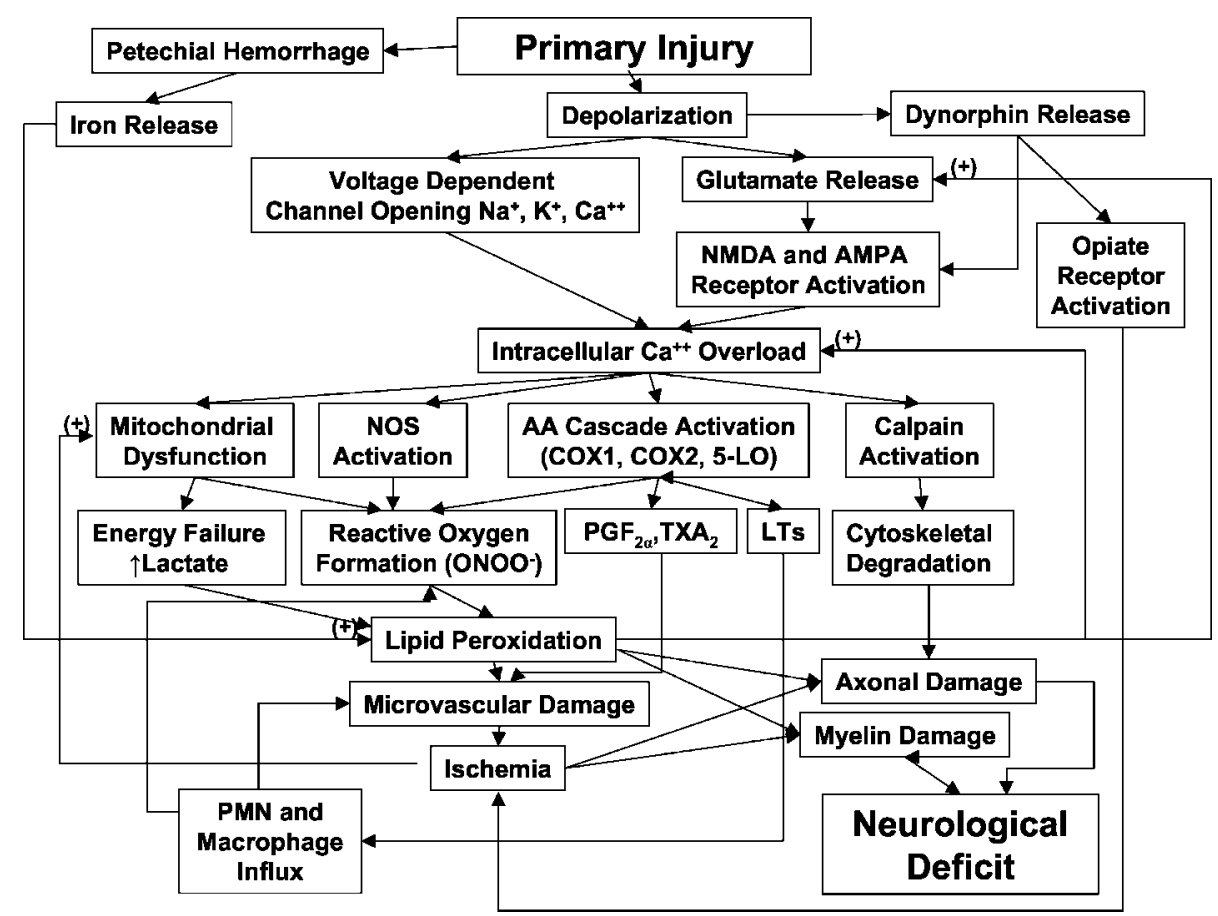

FIG. 1. Pathophysiology of secondary injury in the injured spinal cord. 5 -LO $=5$-lipoxygenase; TXA $_{2}=$ thromboxane $A_{2}$; LTs $=$ leukotrienes; $\mathrm{ONOO}^{-}=$peroxynitrite anion; $\mathrm{PMN}=$ polymorphonuclear leukocyte.

volved in the secondary cascade of events occurring during the first minutes, hours, and days after traumatic SCI. The most immediate event is mechanically induced depolarization and the consequent opening of voltagedependent ion channels (i.e., $\mathrm{Na}^{+}, \mathrm{K}^{+}, \mathrm{Ca}^{2+}$ ). This leads to massive release of a variety of neurotransmitters including glutamate, which can cause the opening of glutamate receptor-operated ion channels (e.g., NMDA, AMPA). Probably the most important consequence of these rapidly evolving ionic disturbances is the accumulation of intracellular $\mathrm{Ca}^{2+}$ (i.e., $\mathrm{Ca}^{2+}$ overload) which initiates several damaging effects. These include: 1) mitochondrial dysfunction, leading to a failure of aerobic energy metabolism and lactate accumulation, 2) activation of mitochondrial and cytoplasmic nitric oxide synthase (NOS) and nitric oxide production, 3) activation of phospholipase $\mathrm{A}_{2}$, which liberates arachidonic acid (AA), which is then converted by cyclooxygenases $(\mathrm{COX} 1,2)$ to a number of deleterious prostanoids such as the potent vasoconstrictor prostaglandin $\mathrm{F}_{2 \alpha}\left(\mathrm{PGF}_{2 \alpha}\right)$ and the vasoconstrictor/platelet aggregation promoter thromboxane $\mathrm{A}_{2}\left(\mathrm{TXA}_{2}\right)$, and by lipoxygenases to the leukotrienes (LTs), some of which are chemoattractants for polymorphonuclear leukocyte and macrophage influx, and 4) activation of the calcium-activated cysteine protease calpain which possesses several substrates including cytoskeletal proteins.

One of the consequences of mitochondrial dysfunction, COX and lipoxygenase activity, and NOS activation is the formation of reactive oxygen species (ROS) including peroxynitrite anion $\left(\mathrm{ONOO}^{-}\right)$, which is a product of the reaction of superoxide radical with nitric oxide. Although peroxynitrite can trigger cellular damage by a variety of mechanisms, cell membrane (plasma and organellar) lipid peroxidation (LP) has been conclusively demonstrated to be a key mechanism. ${ }^{2,3,7,8}$ However, iron is a powerful catalyst that accelerates the propagation of LP reactions. Glycolytically derived lactate promotes LP by stimulating the release of iron from storage sites, e.g., ferritin. In addition, primary and secondary petechial hemorrhages supply hemoglobin-bound iron. LP occurs in neurons and blood vessels, directly impairing neuronal and axonal membrane function and integrity, and causing microvascular damage and secondary ischemia that indirectly contributes to the secondary neuronal injury. Trauma-induced release of endogenous opiates, most importantly dynorphin A, exacerbates the secondary injury process by stimulating NMDA receptors and by activating opiate receptors, the latter contributing to vascular dysfunction, and ionic and metabolic disturbances. ${ }^{5,6,9}$ These secondary injury events are contributed to by more recently described post-traumatic apoptotic processes that will be discussed later in this review.

\section{EMPIRICAL USE OF GLUCOCORTICOID STEROIDS AND EVALUATION OF METHYLPREDNISOLONE THERAPY IN NASCIS I}

The glucocorticoid steroids, mainly dexamethasone and methylprednisolone (MP), were extensively em- 
ployed in the clinical treatment of spinal cord trauma beginning in the mid-1960s and throughout the 1970s. The mechanistic rationale for their use initially centered on the expectation that they would reduce post-traumatic spinal cord edema. This notion was based upon the rather remarkable reduction of peritumoral brain edema that glucocorticoids can induce in brain tumor patients. ${ }^{10}$ Furthermore, steroid pretreatment became a standard of care before neurosurgical procedures to prevent intraand post-operative brain swelling. A limited amount of experimental evidence supported the possibility that glucocorticoid dosing in animal SCI models might be neuroprotective. ${ }^{10}$

In the mid-1970s, a randomized, multi-center clinical trial was organized to determine if steroid dosing was beneficial in improving neurological recovery in humans after SCI. This trial was named the National Acute Spinal Cord Injury Study (NASCIS I). It compared the efficacy of "low-dose" MP (100 mg intravenous bolus/ day for 10 days) and "high-dose" MP (1,000 mg intravenous bolus/day for 10 days) in affecting outcome after SCI. ${ }^{11,12}$ The trial, which began in 1979, did not involve a placebo group due to the prevailing belief that glucocorticoid dosing was probably beneficial and could not be ethically withheld. However, the results failed to show any difference between the low- and high-dose groups at either 6 months ${ }^{11}$ or 1 year, ${ }^{12}$ suggesting to the investigators that steroid dosing was of little benefit. Additionally, there was a suggestion that the 10-day high-dose regimen increased the risk of infections, a predictable side effect of sustained glucocorticoid dosing. Based upon the negative results of NASCIS I, as well as waning neurosurgical enthusiasm for steroid treatment of CNS injury in general, the majority of neurosurgeons concluded after NASCIS that the conventional use of steroids in the acute management of spinal trauma was not beneficial while at the same time being fraught with the potential for serious side effects.

\section{DISCOVERY OF HIGH-DOSE MP THERAPY}

\section{High-dose MP inhibition of LP}

Increasing knowledge of the post-traumatic LP mechanism in the 1970s and early 1980s prompted the search for a neuroprotective pharmacologic strategy aimed at antagonizing oxygen radical-induced LP in a safe and effective manner. Attention was focused on the hypothetical possibility that glucocorticoid steroids might be effective inhibitors of post-traumatic LP based upon their high lipid solubility and known ability to intercalate into artificial membranes between the hydrophobic polyunsaturated fatty acids of the membrane phospholipids and to thereby limit the propagation of LP chain reactions throughout the phospholipid bilayer. ${ }^{13-16}$

One of the present authors (E. D. H.) became inter-

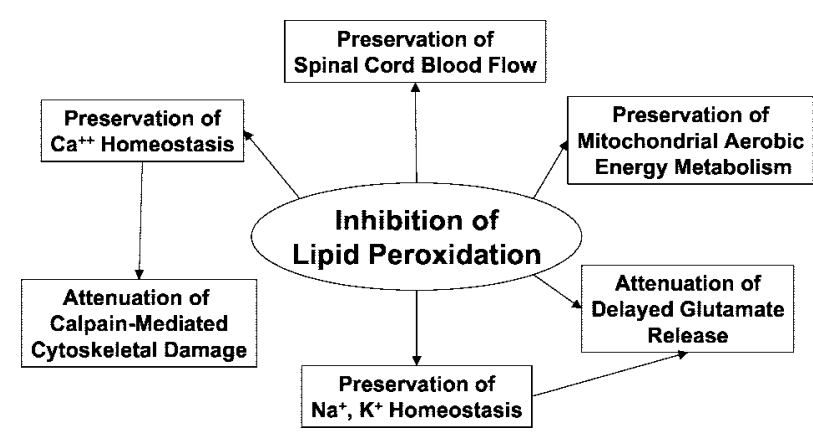

FIG. 2. Hypothesized central role of inhibition of LP in the neuroprotective effects of high-dose MP in acute SCI.

ested in the LP hypothesis of secondary SCI during our parallel investigations of the effects of high-dose MP (15 to $90 \mathrm{mg} / \mathrm{kg}$ i.v.) on spinal cord electrophysiology, as those might serve to improve impulse conduction and recovery of function in the injured spinal cord. ${ }^{17}$ Consequently, it was decided to test the possibility that a similar high-dose of MP, which enhanced spinal neuronal excitability and impulse transmission, might also be required to inhibit post-traumatic spinal cord LP. In an initial set of experiments in cats, it was observed that the administration of an i.v. bolus of MP could indeed inhibit post-traumatic LP in spinal cord tissue, ${ }^{15}$ but that the doses required for this effect were much higher $(30 \mathrm{mg} /$ $\mathrm{kg}$ ) than previously hypothesized or than those empirically employed in the clinical treatment of acute CNS injury or tested in the NASCIS trial. Further experimental studies, also conducted in cat SCI models, showed that the $30-\mathrm{mg} / \mathrm{kg}$ dose of MP not only prevented LP, but in parallel inhibited post-traumatic spinal cord ischemia, ${ }^{18,19}$ supported aerobic energy metabolism (i.e., reduced lactate and improved ATP and energy charge), ${ }^{20-22}$ improved recovery of extracellular calcium (i.e., reduced intracellular overload), ${ }^{19}$ and attenuated calpain-mediated neurofilament loss. ${ }^{22}$ However, the central effect in this protective scenario is the inhibition of post-traumatic LP (FIG. 2). With many of these therapeutic parameters (LP, secondary ischemia, aerobic energy metabolism), the dose-response for MP follows a sharp U-shaped pattern. The neuro- and vaso-protective effect is partial with a dose of $15 \mathrm{mg} / \mathrm{kg}$, it is optimal at $30 \mathrm{mg} / \mathrm{kg}$ and diminishes at higher doses $(60 \mathrm{mg} / \mathrm{kg}){ }^{14}$

The antioxidant neuroprotective action of MP is closely linked to the drug's tissue pharmacokinetics. ${ }^{14,21,23,24}$ For instance, when MP tissue levels are at their peak following administration of a $30 \mathrm{mg} / \mathrm{kg}$ i.v. dose, lactate levels in the injured cord are suppressed. When tissue MP levels decline, spinal tissue lactate rises. However, the administration of a second dose $(15 \mathrm{mg} / \mathrm{kg}$ i.v.) at the point at which the levels after the first dose have declined by $50 \%$, acts to maintain the suppression of lactate seen at the peak of the first dose and to more effectively maintain ATP generation and energy charge 
TABLE 1. Pharmacological Characteristics of HighDose MP Therapy for Acute SCI

- Inhibition of post-traumatic lipid peroxidation appears to be the principal neuroprotective mechanism and this is unrelated to glucocorticoid receptor-mediated actions

- Microvascular and neuroprotective effects are both involved

- Large intravenous doses are required $(30 \mathrm{mg} / \mathrm{kg})$

- Antioxidant protective effects of MP follow a biphasic (U-shaped) dose-response curve; doubling the dose from 30 to $60 \mathrm{mg} / \mathrm{kg}$ results in a loss of the protective efficacy

- Early treatment is required since lipid peroxidation develops rapidly and is irreversible

- Time course of antioxidant protection parallels the spinal cord tissue pharmacokinetics; there is consequently a need for constant i.v. infusion to maintain effective tissue concentrations

- Optimal treatment duration is uncertain, but needs to continue as long as conditions within the injured spinal cord favor lipid peroxidative reactions (i.e., at least 24 to $48 \mathrm{~h}$ )

- Glucocorticoid receptor-mediated anti-inflammatory effects play only a minor role in comparison to lipid antioxidant effects

and protect spinal cord neurofilaments from degradation. ${ }^{21,22}$ This prompted the hypothesis that prolonged MP therapy might better suppress the secondary injury process and lead to better outcomes compared to the effects of a single large i.v. dose. Indeed, subsequent experiments in a cat spinal injury model demonstrated that animals treated with MP using a 48-h antioxidant dosing regimen had improved recovery of motor function over a 4-week period. ${ }^{25,26}$ Table 1 summarizes the neuroprotective pharmacology of high doses of MP derived from acute SCI models.

It should be pointed out that all of the original preclinical studies defining the antioxidant neuroprotective pharmacology showing that high-dose MP could exert antioxidant and related neuroprotective effects were conducted in cat models of blunt (non-transecting) SCI that were the standard in the experimental SCI field before the 1990s. Since that time, rat contusion and compression models have become the standard, and several investigators have tested the ability of high-dose MP (usually $30 \mathrm{mg} / \mathrm{kg}$ i.v. as a starting dose) to lessen posttraumatic pathophysiology and neurodegeneration and/or to improve neurological recovery. Several of these studies have replicated in some manner or another the neuroprotective properties of MP in the injured rat spinal cord. Specifically, high-dose MP has been reported in rat SCI models to attenuate post-traumatic $\mathrm{LP},{ }^{27}$ decrease lactate accumulation, ${ }^{28}$ prevent hypoperfusion, ${ }^{29}$ attenuate vascular permeability, ${ }^{30}$ decrease inflammatory markers, ${ }^{31}$ and improve neurological recovery ${ }^{29,32}$ reminiscent of similar effects shown earlier in cat mod- els. ${ }^{14,16}$ In contrast, failures of high-dose MP to improve neurological recovery in rat SCI models have also appeared in the literature. ${ }^{33,34}$ However, of considerable concern in the extrapolation of the cat MP dosing parameters to the rat is the lack of any definition thus far of the relative pharmacokinetics of MP in rats. This is in striking contrast to the documentation of the uptake and elimination of MP from the cat spinal cord and correlation of plasma and spinal tissue levels with the neuroprotective actions. ${ }^{14,21,23,24}$ The likelihood that the precise dose-response relationship and requirements for repeated dosing defined in cats is also optimal for the rat is exceedingly small. Thus, the interpretation of rat SCI studies with MP, whether positive or negative, is difficult without the necessary pharmacokinetic correlation.

\section{Comparison of the antioxidant effects of different glucocorticoids}

The early empirical treatment of peritumoral edema and acute SCI with glucocorticoid steroids was heavily biased toward the use of dexamethasone based upon the fact that it was, and is, the most potent synthetic glucocorticoid steroid available for parenteral use. Dexamethasone is about five times more potent than MP in regards to glucocorticoid receptor affinity and anti-inflammatory potency. ${ }^{35}$ However, it has been found that the antioxidant efficacy of MP is unrelated to its glucocorticoid steroid receptor activity. ${ }^{36}$ Indeed, a careful concentration-response study has compared the ability of different glucocorticoid steroids to inhibit oxygen-radical-induced LP damage in rat brain synaptosomal preparations, and confirmed that LP-inhibiting potencies and anti-inflammatory potencies do not correlate. Although dexamethasone is five times more potent than MP as a glucocorticoid, it is only slightly more potent than MP as an inhibitor of LP. ${ }^{37}$ Furthermore, the maximal antioxidant activity of MP appears to be superior to that for dexamethasone. The prototype glucocorticoid hydrocortisone is completely lacking in ability to inhibit oxygen radical damage in CNS tissue. Thus, the choice of a steroid for its potential antioxidant neuroprotective activity should not be predicated on glucocorticoid receptor-mediated anti-inflammatory actions. In addition, the choice of the most potent glucocorticoid would logically carry the greatest potential for concomitant steroid-related side effects.

\section{DISCOVERY OF NALOXONE THERAPY FOR ACUTE SCI}

Concurrent with the discovery of the neuroprotective efficacy of high-dose MP in animal models of SCI, others were demonstrating the ability of the opiate receptor antagonist naloxone to improve recovery after experimental SCI. The rationale for the study of naloxone in 
acute SCI models was based upon its positive effects in experimental shock models. ${ }^{38,39}$ Studies in cat SCI models, carried out in two separate laboratories, documented the ability of naloxone to maintain spinal cord blood flow $^{40}$ and to improve neurological recovery after contusion SCI. ${ }^{9,40-42}$ Furthermore, a phase I study in acute SCI patients showed that the drug was safe in that population. $^{43}$

\section{NASCIS II CLINICAL TRIAL OF HIGH-DOSE MP AND NALOXONE}

The above-reviewed experimental studies with highdose MP and naloxone inspired the second National Acute Spinal Cord Injury Study (NASCIS II), ${ }^{44}$ even though the earlier NASCIS trial, which came to be known as NASCIS I, had failed to show any efficacy of lower MP doses even when administered over a 10-day period. ${ }^{11,12}$ The NASCIS II trial compared $24 \mathrm{~h}$ of dosing with MP or naloxone versus placebo for the treatment of acute SCI. A priori trial hypotheses included the prediction that SCI patients treated within the first $8 \mathrm{~h}$ postinjury would respond better to pharmacotherapy than patients treated after $8 \mathrm{~h}$. Indeed, the results demonstrated the effectiveness of $24 \mathrm{~h}$ of intensive MP dosing ( $30 \mathrm{mg} / \mathrm{kg}$ i.v. bolus plus a $23-\mathrm{h}$ infusion at $5.4 \mathrm{mg} / \mathrm{kg}$ per hour) when treatment was initiated within $8 \mathrm{~h}$. Significant benefit was observed in individuals with both neurologically complete (i.e., plegic) and incomplete (i.e., paretic) injuries. Moreover, the functional benefits were sustained at 6-week, 6-month, and 1-year followups. ${ }^{44-47}$ The high-dose regimen actually improved function below the level of the injury and lowered the level of the functional injury. ${ }^{46}$ Although predictable side effects of steroid therapy were noted, including GI bleeding, wound infections and delayed healing, these were not significantly more frequent than those recorded in placebo-treated patients. ${ }^{44}$ Another finding was the fact that delay in the initiation of MP treatment until after $8 \mathrm{~h}$ is actually associated with decreased neurological recovery. ${ }^{46}$ Thus, treatment within the 8 -h window is beneficial whereas dosing after $8 \mathrm{~h}$ can be detrimental. Possible explanations for this latter effect are discussed below.

The original NASCIS II publications ${ }^{44,45}$ rather cryptically stated that in contrast to the beneficial actions of high-dose MP, the opiate receptor naloxone did not significantly improve the return of sensory or motor function. However, in a subsequent analysis, naloxone was shown to have improved neurological function below the lesion in patients with incomplete injuries. ${ }^{46}$ Thus, in the case of both high-dose MP and naloxone, at least a partial validation of the positive effects of these two therapeutic approaches and compounds in animal models of SCI was achieved in the placebo-controlled NASCIS II trial.

\section{Possible role of anti-inflammatory effects in neuroprotective efficacy of MP}

The rationale for the high-dose MP arm of the NASCIS II trial was derived from the animal studies showing that the steroid can inhibit post-traumatic LP and associated pathophysiological events. ${ }^{14}$ The positive effects of high-dose MP obtained in NASCIS II were at least tentatively viewed as a validation of the LP hypothesis. ${ }^{44-46}$ However, following the publication of the NASCIS II results, it was suggested that a complete assignment of the mechanism of the MP neuroprotective effect to the inhibition of LP was premature. After all, the glucocorticoid steroid MP possesses various glucocorticoid receptor-mediated anti-inflammatory actions that could reasonably be expected to play a neuroprotective role in addition to the non-glucocorticoid LP inhibition.

In view of the known importance of certain prostanoids $\left(\mathrm{PGF}_{2 \alpha}\right.$ and $\mathrm{TXA}_{2}$ ) in post-traumatic pathophysiology (FIG. 1), it is conceivable that MP, by virtue of its phospholipase $\mathrm{A}_{2}$ inhibitory action, might protect the injured spinal cord by inhibiting AA release, and consequently attenuating the formation of these deleterious prostanoids. In support of this possible mechanism, it has been shown that pre-treatment of cats with a $30 \mathrm{mg} / \mathrm{kg}$ i.v. dose of MP does reduce post-traumatic spinal cord AA release, as well as $\mathrm{PGF}_{2 \alpha}$ and $\mathrm{TXA}_{2}$ formation. ${ }^{48}$ However, the assumption that this effect is due entirely to the well-known ability of glucocorticoids to inhibit phospholipase $A_{2}$ is not tenable for three reasons. First of all, the glucocorticoid inhibition of phospholipase $A_{2}$ is mediated via the interaction of the steroid with specific glucocorticoid receptors, an action that most certainly does not require a $30 \mathrm{mg} / \mathrm{kg}$ i.v. dose to be fully manifested; much lower doses should suffice. Secondly, the reported spinal cord glucocorticoid receptor population ${ }^{49}$ involved in this activity would be saturated at much lower glucocorticoid doses. Thirdly, the reduction of post-traumatic spinal cord AA release (and reduced prostanoid formation downstream) may simply be secondary to an attenuation of LP since peroxidative reactions can liberate arachidonate independent of phospholipase $\mathrm{A}_{2}$ activity. In other words, the MP effect on prostanoid build-up in the injured spinal cord may be an indirect result of lessened membrane LP. Fairly convincing support for this view comes from the fact that pre-treatment of cats with the lipid antioxidant vitamin $\mathrm{E}$ also reduced post-traumatic AA liberation and accumulation of $\mathrm{PGF}_{2 \alpha}$ and $\mathrm{TXA}_{2} \cdot{ }^{48}$ Furthermore, subsequent studies showed that the administration of antioxidant neuroprotective doses of MP (i.e., $30 \mathrm{mg} / \mathrm{kg}$ i.v.) at $30 \mathrm{~min}$ after moderately severe compression SCI in cats did not attenuate the post-traumatic elevation in $\mathrm{PGF}_{2 \alpha}$ or $\mathrm{TXA}_{2} .{ }^{50}$ There- 
fore, it is unlikely that the protective effects of MP on the injured cord are more a reflection of the phospholipase $\mathrm{A}_{2}$-inhibiting activity than its antioxidant property.

Similarly, the administration of neuroprotective doses of MP in a rat model of contusion SCI also failed to significantly reduce the infiltration of polymorphonuclear leukocyte (PMN) into the injured cord. ${ }^{30}$ On the other hand, another group has reported that a single high dose of MP can significantly suppress PMN and macrophage influx into the rat cord following a partial transaction injury, although this effect was not associated with a reduction of secondary neurodegeneration..$^{51}$

Despite this confusing body of data concerning the possible involvement of anti-inflammatory mechanisms for MP neuroprotection in acute SCI, inflammatory processes play an increasingly appreciated role in post-SCI secondary injury. ${ }^{52,53}$ Moreover, glucocorticoid steroids, including MP, possess a wide array of anti-inflammatory mechanisms and are probably the most potent and reliable anti-inflammatory agents in the current pharmacological armamentarium. ${ }^{35}$ Thus, these facts open up the possibility that particular anti-inflammatory mechanisms may play some role in the MP neuroprotective activity. In that regard, high doses of MP have been more recently reported to attenuate the post-traumatic expression of the pro-inflammatory mediators activator protein-1 (AP-1) and nuclear factor $\kappa \mathrm{B}(\mathrm{NF} \kappa \mathrm{B})$ and matrix metalloproteinase 1 and 9 in the injured spinal cord, although this study employed a relatively mild level of injury. ${ }^{31} \mathrm{Re}-$ cently, a role of delayed influx of $\mathrm{T}$ cells has been suggested to be involved in secondary SCI. ${ }^{54,55}$ Considering that glucocorticoids also suppress T-cell-mediated hypersensitivity in a variety of conditions, ${ }^{35}$ there is a strong possibility that high-dose MP may have an impact on this immune response in the injured spinal cord, although this has not been investigated in SCI models.

\section{DISCOVERY OF THE NON- GLUCOCORTICOID STEROID TIRILAZAD}

MP is a potent glucocorticoid that possesses a number of glucocorticoid receptor-mediated anti-inflammatory actions. Despite the above-discussed role of anti-inflammatory effects of MP in the injured spinal cord, the principal neuroprotective mechanism appears to be the inhibition of post-traumatic LP that is not mediated via glucocorticoid receptor-mediated activity. ${ }^{56-58}$ This prompted speculation that modifying the steroid molecule to enhance the anti-LP effect, while eliminating the glucocorticoid effects of the steroid, would result in more targeted antioxidant therapy devoid of the typical side effects of steroid therapy. This rationale led to the development of more potent LP inhibitors, the 21-aminosteroids or "lazaroids," which lack the glucocorticoid receptor-mediated side effects that limit the clinical utility of high-dose MP. One of these, tirilazad,<smiles>CC1CC2C(C(O)CC3(C)C2CC[C@@]3(O)C(=O)COCCC(=O)[O-])C2(C)C=CC(=O)C=C12</smiles>

Methylprednisolone sodium succinate

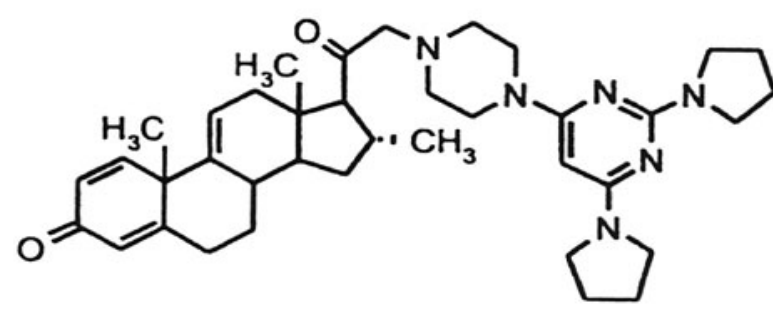

Tirilazad Mesylate U-74006F

FIG. 3. Chemical structures of the glucocorticoid steroid MP shown as the sodium salt of the 21 -hemisuccinate ester and the non-glucocorticoid 21-aminosteroid tirilazad mesylate.

was selected for development. FIG. 3 compares the structures of the glucocorticoid, MP, and the non-glucocorticoid 21-aminosteroid, tirilazad.

\section{NASCIS III}

The demonstrated efficacy of a 24-h dosing regimen of MP in human SCI in NASCIS II ${ }^{44}$ and the discovery of tirilazad ${ }^{56-58}$ led to the organization and conduct of NASCIS III..$^{59,60}$ In the NASCIS III trial, three groups of patients were evaluated. The first (active control) group was treated with the 24-h MP dosing regimen that had previously been shown to be effective in NASCIS II. The second group was also treated with MP, except that the duration of MP infusion was prolonged to $48 \mathrm{~h}$. The purpose was to determine whether extension of the MP infusion from 24 to $48 \mathrm{~h}$ resulted in greater improvement in neurological recovery in acute SCI patients. The third group of patients was treated with a single $30 \mathrm{mg} / \mathrm{kg}$ i.v. bolus of MP followed by the 48-h administration of tirilazad. No placebo group was included because it was deemed ethically inappropriate to withhold at least the initial large bolus of MP. Another objective of the study was to ascertain whether treatment initiation within $3 \mathrm{~h}$ following injury was more effective than when therapy was delayed until 3 to $8 \mathrm{~h}$ post-SCI.

Upon completion of the NASCIS III trial, it was found that all three treatment arms produced comparable degrees of recovery when treatment was begun within the 
shorter 3-h window. When the 24-h dosing of MP began more than $3 \mathrm{~h}$ post-SCI, recovery was poorer in comparison to the cohort treated within $3 \mathrm{~h}$ following SCI. However, in the 3 to $8 \mathrm{~h}$ post-SCI cohort, when MP dosing was extended to $48 \mathrm{~h}$, significantly better recovery was observed than with the $24 \mathrm{~h}$ dosing. In the comparable tirilazad cohort ( 3 to $8 \mathrm{~h}$ post-SCI), recovery was slightly, but not significantly better than in the 24-h MP group, and poorer than in the 48-h MP group. These results showed that: 1) initiation of high-dose MP treatment within the first $3 \mathrm{~h}$ is optimal, 2) the non-glucocorticoid tirilazad is as effective as 24-h MP therapy, and 3) if treatment is initiated more than $3 \mathrm{~h}$ post-SCI, extension of the MP dosing regimen is indicated, from $24 \mathrm{~h}$ to $48 \mathrm{~h}$. However, in comparison with the 24-h dosing regimen, significantly more glucocorticoid-related immunosuppression-based side effects were seen with more prolonged dosing (i.e., the incidence of severe sepsis and pneumonia significantly increased). In contrast, tirilazad showed no evidence of steroid-related side effects, suggesting that this non-glucocorticoid 21-aminosteroid would be safer for extension of dosing beyond the 48-h limit used in NASCIS III. ${ }^{59,60}$

\section{LIMITATIONS TO THE USE OF HIGH-DOSE MP IN ACUTE SCI}

The use of large doses of glucocorticoid steroids in SCI patients has appropriately been referred to as a "twoedged sword." ${ }^{\prime}$ This is derived from the fact that the neuroprotective properties of MP can be offset by the potential of the necessary high doses of MP to elicit glucocorticoid receptor-mediated side effects that could compromise the neurological outcome and even the survival of acute SCI patients. This is most apparent when treatment is extended beyond the apparently safe limit of $24 \mathrm{~h}$ demonstrated in NASCIS II. Complications of highdose MP, including increased incidence of pneumonias, pressure sores, GI bleeding, and deep vein thrombosis, have also been documented when the NASCIS II dosing is used as a prophylactic neuroprotectant for spinal surgery. ${ }^{62}$ However, there are other glucocorticoid-related actions, that although not necessarily life-threatening, can potentially complicate the steroid's proper usage in SCI patients and/or counteract its neuroprotective actions. These are listed in Table 2.

\section{Biphasic (U-shaped) neuroprotective dose response}

The sharp U-shaped dose-response curve for the neuroprotective properties of MP, and the need for repeated dosing (i.e., continuous infusion) to maintain these effects $^{14}$ make the administration of MP in SCI patients difficult, and even tricky. For instance, optimal doses of MP can lessen post-traumatic anaerobic metabolism in the injured spinal cord and lessen lactate accumula-
TABLE 2. Limitations and Difficulties Associated with High-Dose MP Therapy of Acute SCI

- Risk of glucocorticoid steroid receptor-mediated side effects

○ Infection-pneumonia and septic shock

$\circ$ Diabetic complications

$\circ$ Delayed wound healing

- Sharp biphasic dose-response curve requires care in dose calculation and administration (i.e., little room for error)

- Needed duration of dosing ( 24 vs. 48 h) dependent upon time to initiation of treatment

- Initiation of treatment beyond the 8-h window can exacerbate damage; inhibition of membrane phospholipase $A_{2}$ can impede clean-up of peroxidized lipids and aggravate peroxidative damage

- Glucocorticoid dosing can inhibit axonal sprouting and synaptogenesis; attenuation of regenerative responses

tion, ${ }^{21,22,24}$ and inadequate or excessive MP dosing has been shown to aggravate post-traumatic lactate accumulation. $^{21,22,24}$ This is a consequence of glucocorticoid receptor-mediated gluconeogenesis stimulatory actions by MP and similar steroids. As a result, there is opposition between the beneficial effects of optimal MP doses to support aerobic metabolism and to lessen lactate accumulation while non-optimal doses can result in lactate production being enhanced via an increase in blood glucose levels. The latter can potentially drive up anaerobic glycolysis in the injured cord which will aggravate, rather than inhibit, LP reactions. Thus, considerable care is required in dose calculation whether it is based upon body weight or mass because too little will not serve to effectively protect, and too much will result in a loss of the antioxidant neuroprotection.

During the last 13 post-NASCIS II years of widespread use of high-dose MP (NASCIS II $24 \mathrm{~h}$ or NASCIS III $48 \mathrm{~h}$ protocols), there have undoubtedly been many dose miscalculations that have resulted in lessthan- or more-than-optimal MP dosing in many SCI patients. As Bracken ${ }^{63}$ notes, there are only ad hoc reports of compliance to the $24 \mathrm{~h}$ NASCIS II MP dosing protocol in routine practice. However, these include reports of therapy commencing later than the recommended $8 \mathrm{~h}$ cutoff, discontinuation of therapy before $24 \mathrm{~h}$, accidental administration of the full 24-h dose within the first hour, the maintenance infusion being given at rates faster or slower than the recommended $5.4 \mathrm{mg} / \mathrm{kg} / \mathrm{h}$ and inaccurate estimates of patient body weight. Similarly, the first author has listened to several anecdotes over the past several years concerning MP dose miscalculations either in regards to the magnitude of the initial bolus-loading dose or the rate and duration of the maintenance infusion. The rather narrow $\mathrm{U}$-shaped dose-response curve dictates that great care be taken in calculating and administering the NASCIS II or III MP protocols. Based upon 
the experimentally determined U-shaped dose-response curve, the need for initiation of treatment as soon as possible and the requirement for maintenance dosing to maintain the neuroprotective effects during the first 24 to $48 \mathrm{~h}$, it is likely that MP will have no benefit if the protocol is erroneously administered.

\section{Duration of treatment dependent on treatment initiation time}

The results of the NASCIS III study show that if treatment cannot be initiated until after the first 3 posttraumatic hours, then it would be better to extend the infusion phase of the treatment from 24 to $48 \mathrm{~h}$. On the other hand, if begun within the first $3 \mathrm{~h}$, the $24 \mathrm{~h}$ NASCIS II protocol is sufficient. ${ }^{59,60}$ Thus, attention to the time of injury versus treatment initiation time is an important consideration that adds a small but significant complication to the therapy.

\section{Late treatment initiation may exacerbate damage}

Initiation of MP therapy beyond the $8 \mathrm{~h}$ therapeutic window determined in NASCIS II may actually exacerbate the post-traumatic secondary injury and lessen the expected neurological outcome compared to no therapy. ${ }^{46}$ This is most likely due to the fact that MP inhibition of membrane phospholipase $\mathrm{A}_{2}$ can impede the clean-up of peroxidized lipids. Therefore, the need to take into account the exact time of injury in making the decision to treat or not to treat the SCI patient with high-dose MP is yet another complicating factor. Treatment later than $8 \mathrm{~h}$ post-injury should be avoided.

\section{Possible negative effects on neuronal survival and plasticity}

Glucocorticoids have been repeatedly shown to inhibit axonal sprouting and synaptogenesis in various CNS areas. ${ }^{64-67}$ Although it is not known whether these actions will occur concomitantly with the acute antioxidant neuroprotective effects, the potential of the steroid to attenuate post-traumatic plasticity mechanisms is perhaps the most serious concern regarding the administration of high doses of MP for any longer than necessary. Although the beneficial neurological effects of $24 \mathrm{~h}$, and even $48 \mathrm{~h}$ of dosing seen in NASCIS II and III, respectively, might suggest that the anti-plasticity effects are not a problem with short-term high-dose MP therapy, this has not been investigated.

Other neurotoxic actions documented in certain neuronal populations (e.g., hippocampus) with either physiological or pharmacological levels of glucocorticoids ${ }^{68-76}$ give pause when administering high doses of a glucocorticoid steroid in the context of the injured CNS. Although the sensitivity of spinal cord neurons to these detrimental actions of glucocorticoids has not been specifically investigated, the possibility that high-dose MP therapy may aggravate post-traumatic neuronal dam- age begs further investigation. If in fact the plasticityinhibiting and neurotoxic actions of glucocorticoids are shown to occur in the injured cord coincident with the neuroprotective antioxidant actions this will be yet another example of how MP can constitute a "two-edged sword" in the treatment of acute SCI. In any event, the potential for steroid side effects, inhibition of plasticity mechanisms and even neurotoxic actions underscores the fact that glucocorticoids such as MP are a far-from-ideal approach to dealing with the post-traumatic oxidative stress and LP-related damage and consequent need for antioxidant dosing that continues beyond the first 24 to $48 \mathrm{~h}$. The realization of these limitations was the impetus for the discovery of the non-glucocorticoid steroid tiril$\operatorname{azad}^{56,57}$ to provide a LP-inhibiting steroid that would be easier to use and be devoid of the detrimental CNS and non-CNS aspects of glucocorticoid steroids. Tirilazad's ability to improve neurological recovery in NASCIS III at least as well as MP (i.e., treatment within $3 \mathrm{~h}$ postinjury) while producing fewer side effects ${ }^{59,60}$ strongly suggest that it is worthy of additional trials in acute SCI that could ultimately show greater efficacy and safety in comparison to high-dose MP.

Despite concerns about the potential inhibition of axonal sprouting and other neurotoxic actions of glucocorticoids discussed above, it is encouraging in regards to the safety and neuroprotective value of the ongoing clinical use of high doses of MP in SCI therapy that high doses of MP have actually been reported to lessen axonal dieback of vestibulospinal fibers and to promote their terminal sprouting in transected rat spinal cords. ${ }^{77}$ The same group has shown that identical high doses of MP can improve axonal regeneration into Schwann cell grafts $^{78}$ and lessen caspase- 3 activation ${ }^{79}$ in transected rat spinal cords. In regards to the latter anti-apoptotic action, other labs have also shown that high-dose MP therapy can lessen apoptotic neurodegeneration after traumatic $^{80}$ or ischemic ${ }^{81} \mathrm{SCI}$ in rats. These effects were achieved with acute MP administration limited to the first $4 \mathrm{~h}$ after injury. In contrast, a recent report has shown that MP can exacerbate retinal ganglion cell apoptosis in the context of autoimmune CNS inflammation. ${ }^{82}$ Thus, the question of whether high-dose MP is neuroprotective or neurotoxic may depend on dose selection, timing, and duration of administration and the particular neuronal population in question.

\section{EVALUATION OF MONOSIALOGANGLIOSIDE (GM-1) IN ACUTE SCI}

Besides MP and naloxone, the only other drug to have been tested in phase III trials in SCI patients is the monosialoganglioside compound GM1 (also called Sygen). This compound was shown as far back as the 1970s to exert neuroprotective and neuroregenerative effects in 
a variety of animal models of neural injury ${ }^{83-86}$ although it was never tested in an acute SCI model per se. Nevertheless, it captured the interest of non-NASCIS investigators in regards to the desire to conduct clinical trials of its potential benefits in acute SCI. An initial small single-center phase II trial of 37 patients suggested that the administration of GM1 to SCI patients within $24 \mathrm{~h}$ after injury might lead to an improvement in neurological recovery. ${ }^{87,88}$ Subsequently, the same investigator led a multi-center phase III trial of GM1 in acute SCI patients. Since the organization of this trial occurred after the widespread acceptance of high-dose MP as the standard of care for acute SCI, the effects of GM1 were examined on top of the 24-h NASCIS II high-dose MP protocol. ${ }^{86,89,90}$ The administration of GM1 was begun after the completion of the NASCIS II 24-h MP dosing protocol. ${ }^{86,89,90}$ The results indicated that use of GM1 after MP therapy resulted in a faster achievement of peak neurological recovery, although the extent of functional improvement was not greater than that observed in patients who only received MP.

\section{THE MP SCI CONTROVERSY AND CRITICISM OF THE NASCIS TRIALS}

Before the completion of NASCIS II, there was no treatment for acute SCI that had ever been demonstrated in a placebo-controlled clinical trial to have a beneficial effect on neurological outcome. Therefore, the revelation of the beneficial effects of high-dose MP was a surprise to many in the medical community including some, if not all, of the NASCIS II clinical investigators. So surprising and gratifying were the results that the National Institutes of Health (NIH) sanctioned a pre-publication press release of the results for the purpose of informing the neurosurgical community so that the NASCIS II MP dosing protocol would be immediately available to SCI patients, and they would not have to wait for the initial trial manuscript that had been accepted by the New England Journal of Medicine to appear. The editorial office of the journal uncharacteristically approved the pre-publication release of the findings based upon their view that this indeed represented a breakthrough treatment for acute SCI and it should be immediately available to SCI victims. For the NIH and the NASCIS II group to have done otherwise would undoubtedly have been viewed by many physicians and patients as unethical. However, the negative response of a few neurosurgeons to the idea of publishing clinical trial results in the popular press before publication and before presentation to, and careful scrutiny by, the neurosurgical community represented the beginning of a heated controversy about the design, analysis, and reporting of the NASCIS II ${ }^{12,44,46}$ and later the NASCIS III ${ }^{59,60,91}$ trials. This controversy has raged off and on for the past 13 years.
In 2000, three separate and highly critical reviews appeared in the literature castigating the NASCIS trials and the resulting view that high-dose MP therapy should be considered the standard of care for acute SCI. ${ }^{92-94}$ The first critical review ${ }^{92}$ was written by a single author who is a member of the American Association of Neurological Surgeons/Congress of Neurological Surgeons (AANS/CNS) Practice Guidelines Subcommittee for the Pharmacological Treatment of SCI. However, he was the sole author and a disclosure was included at the end of the paper stating that "the views expressed in this paper do not represent the final consensus of the committee". Therefore, it could be perceived that the other AANS/ CNS committee members did not agree with the negative assessment of high-dose MP therapy for SCI patients.

In any case, Hurlbert ${ }^{92}$ leveled six criticisms of the NASCIS II study. The first of these was that the overall analysis of the effects of either MP or naloxone vs. placebo was negative when all patients were included in the analysis (i.e., no split of patients treated within $8 \mathrm{~h} v s$. after $8 \mathrm{~h}$ ). The further claim was made that the stratified analysis on the basis of time to treatment was a post hoc decision. However, this was not the case in the design of NASCIS II. The rule for subgroup analysis is that if the subgroup is pre-specified in the study protocol then that becomes the primary endpoint. Indeed, the National Institute of Neurological Disorders and Stroke (NINDS) proposal that funded NASCIS II specified that two dichotomies would be studied. Specifically, the effects of early vs. late treatment with MP or naloxone would be analyzed, as well as the effects of either drug in incomplete and complete SCI patients. ${ }^{63}$ The precise time of the data cut was not pre-specified due to the fact that going into the trial; there was no way to know what the median treatment initiation time would be. After the final patient was enrolled, it turned out that $8 \mathrm{~h}$ was the nearest whole number to the median treatment initiation time $(8.5 \mathrm{~h})$, and thus $8 \mathrm{~h}$ was selected for the data-split. ${ }^{63}$ This approach has similarly been used and widely accepted in establishing the 3-h cutoff for the safe and effective use of tissue plasminogen activator in acute stroke therapy. ${ }^{95,96}$ Therefore, the claim that the NASCIS II trial did not reach its primary endpoint in regards to the efficacy of MP is not consistent with the documented trial design in which the plan to look at early vs. late treatment and the influence of injury severity was in fact pre-planned.

Additional criticisms of NASCIS II put forth by Hurlbert $^{92}$ were that the MP effect sizes were small, their functional importance was uncertain due to the reliance on neurological sensory and motor assessments rather than functional improvement scales, and that effects on long tract function were not established. Each of these has been addressed by additional analyses of the NASCIS II data set carried out by Bracken and col- 
leagues. ${ }^{46,47,63}$ Concerning the size of the effect, it has indeed been acknowledged that the benefits of MP in the context of NASCIS II were "modest, but [MP] does appear to have the potential to result in important clinical recovery in some patients," and that "even small changes in motor recovery, typically assessed in the MPSS trials on one side of the body, have the potential to be amplified into meaningful improvements in the quality of life". ${ }^{63}$ Regarding the issue of long tract vs. segmental recovery effects, further analysis of the NASCIS II data revealed that the greatest degree of motor function recovery within patients receiving MP within the 8-h window occurred in long spinal tracts as recorded below the level of the injury, although significant segmental recovery was also found at the level of the lesion. ${ }^{46,63}$ The criticism that the clinical significance of the functional improvement was not assessed by inclusion of functional or quality-of-life measures such as the Functional Independence Measure (FIM) in NASCIS II is valid. Recently, the NASCIS II principal investigator published an estimate of functional recovery in NASCIS II from results modeled in the NASCIS III study, which did include FIM assessments. In that report, it is claimed that "The extent of MP therapy-related motor function recovery observed in NASCIS II predicted clinically important recovery in the FIM". 91

The final NASCIS II critique by Hurlbert ${ }^{92}$ concerning the questionable safety of high-dose MP therapy in SCI patients is difficult to reconcile with the NASCIS II data set, which found no significant differences in adverse reactions between placebo and MP-treated patients. ${ }^{44,45}$ Since NASCIS II represents the only placebo-controlled trial of a 24-h high-dose regimen in SCI patients, it is difficult to understand the claim that this particular regimen is unsafe. In contrast, the NASCIS III trial showed that extension of the duration of dosing from 24 to $48 \mathrm{~h}$ resulted in an increased incidence of pneumonia and a nearly significant $(p<0.07)$ increase in the occurrence of severe sepsis, which are undoubtedly manifestations of the immunosuppressive properties of intensive glucocorticoid dosing. ${ }^{59}$ Therefore, the available data that directly addresses the safety of high-dose MP in SCI patients in a controlled context shows that the 24-h regimen is not associated with an increase in adverse reactions whereas the 48-h regimen does carry some risk of serious glucocorticoid-related problems. However, this has to be balanced against the results of NASCIS III showing that in patients not treated until after the first $3 \mathrm{~h}$ post-SCI, the extension of dosing to $48 \mathrm{~h}$ produces a significantly better neurological outcome compared to the 24-h regimen. Considering the devastating nature of most SCIs, it seems that the risk of MP treatment is outweighed by the potential benefits to the patient's neurological recovery.

Hurlbert $^{92}$ criticizes the NASCIS III trial on five counts, including the lack of a placebo group, the claim that the overall analysis was negative, that the stratification of patients treated within $3 \mathrm{~h} v s$. between 3 and $8 \mathrm{~h}$ was a post hoc analysis, that the improvement in the FIM score in 48-h MP-treated patients compared to the 24-h MP cohort was modest and finally that MP treatment is unsafe based upon the increased incidence of sepsis and pneumonias. The first of these concerning the lack of a placebo group was addressed earlier in this review. The next two, regarding the statistical analysis, are identical to those leveled against NASCIS II. Here again, the NASCIS III investigators have gone on record stating that the dichotomized analysis of the NASCIS III data on the basis of time to treatment (early vs. late) was a pre-planned and not a post hoc analysis, and therefore qualify as primary endpoints. ${ }^{59,63}$ The issue of the significance of the FIM score improvement shown in 48-h MP patients in NASCIS III requires a careful viewing of the data. Hurlbert ${ }^{92}$ focuses on the fact that in the intent to treat analysis, the improvement in the total FIM score only reached a level of $p<0.08 .^{59}$ However, looking at the subscores reveals a significantly better self-care score in the 48-h treated patients $(p<0.03)$ and sphincter control score $(p<0.01)$. If, however, the analysis is re-done. including only those patients in which the dosing protocols were completely followed, even the total FIM score in the 48-h treated patients reaches the 0.05 level vs. the 24-h MP cohort. In regards to the safety criticism, the 48-h MP group displayed a significant increase in pneumonias and a nearly significant increase in severe sepsis in comparison to the 24-h group. As noted above, these are predictable risks of high-dose glucocorticoid therapy in critically ill patients. The risk to benefit ratio is a matter of personal opinion.

The other two critiques have multiple authors ${ }^{93,94}$ and, similar to Hurlbert, ${ }^{92}$ intensely criticize not only the NASCIS trial design, analysis and reporting, but also that of the preclinical studies that inspired the conduct of NASCIS II and III. As already discussed above, the senior investigator of the NASCIS trials, Dr. Bracken, has addressed the various criticisms and misunderstandings put forth in these in the form of a recent metaanalysis of the NASCIS and non-NASCIS trials of MP in acute SCI, and their overall statistically significant support of the efficacy and safety of high-dose MP therapy for acute SCI. He concludes from the meta-analysis that "high-dose MP given within $8 \mathrm{~h}$ of acute SCI is a safe and modestly effective therapy that may result in important clinical recovery for some patients. Further trials are needed to identify superior pharmacological therapies and to test drugs that may sequentially influence the post-injury cascade". 63

This view is generally endorsed in a recent summary statement in the journal Spine from the Spine Focus Panel, ${ }^{97}$ in which Dr. Michael Fehlings (Toronto, On- 
TABLE 3. Suggested Indications for the Use of MP in Acute $\mathrm{SCI}^{97}$

For acute non-penetrating SCI ( $<3 \mathrm{~h}$ after injury), MP should be given as per NASCIS II protocol (i.e. 24 hours of treatment)

For acute non-penetrating SCI ( $>8 \mathrm{~h}$ after injury), MP should not be used

For acute non-penetrating SCI (after $3 \mathrm{~h}$, within $8 \mathrm{~h}$ ), MP should be given as per NASCIS III protocol (i.e., $48 \mathrm{~h}$ of treatment)

For acute penetrating SCI, MP is not recommended

tario) stated: "Members of the Spine Focus Panel extensively discussed the role of MP in acute SCI but could not reach agreement on key points. While it is acknowledged that the NASCIS trials represent landmark clinical studies, no clear consensus could be reached on the appropriate use of steroids in acute SCI. Many members of the Spine Focus Panel acknowledged that although methylprednisolone is only modestly neuroprotective, this drug is clearly indicated in acute SCI because of its favorable risk/benefit profile and the lack of alternative therapies. However, a significant minority was of the opinion that the evidence supporting the use of steroids in SCI was weak and did not justify the use of this medication. The Spine Focus Panel did agree that given the devastating impact of SCI and the modest efficacy of MP, clinical trials of other therapeutic interventions are urgently needed. Many panel members also felt that a reanalysis of the NASCIS data might help to resolve the controversies surrounding the use of steroids in acute SCI. Of note, Dr. Bracken has agreed to release the data for "protocol-driven research by qualified investigators'."

Following the summary statement, Dr. Fehlings presented an editorial ${ }^{98}$ in which he first summarized the criticisms of NASCIS II and III, followed by a presentation of the "Suggested Indications for the Use of Methylprednisolone in Acute SCI"; these are duplicated in Table 3. He closes the editorial by stating: "Given the devastating impact of SCI and the evidence of a modest, beneficial effect of MP, clinicians should consciously consider using this drug despite the well-founded criticisms that have been directed against the NASCIS II and III trials. With great understanding of the biomolecular events contributing to the pathogenesis of SCI, it is hoped that other neuroprotective agents will enter into clinical practice in the next 5-10 years"

\section{REGULATORY STATUS OF MP, TIRILAZAD, AND GM-1 FOR SCI}

The clinical testing of MP in either NASCIS I or II was much easier than the typical scenario of new drug development, due to the fact that MP had already been successfully developed, approved by the U.S. Food and
Drug Administration (FDA), and marketed over several years for a wide variety of anti-inflammatory conditions. MP in multiple oral, intramuscular, and intravenous formulations was approved in the early 1960s, and the drug was actually off-patent in the U.S. by the time of the initiation of the NASCIS trials. Furthermore, in regards to the testing of high doses of the steroid in SCI patients, there was already considerable clinical experience with the i.v. administration of doses as high or higher than 30 $\mathrm{mg} / \mathrm{kg}$ in several clinical studies concerned with the potential use of MP in various critical care indications. The safety of this high-dose treatment for a short period had already been established, even in severely compromised patients. Therefore, the approval of the Investigational New Drug Application for testing in human SCI did not pose a significant hurdle. Moreover, the trials were not initiated or controlled by the drug's original sponsor (The Upjohn Company, Kalamazoo, MI), but rather by the NASCIS group headed by Dr. Michael Bracken (Epidemiology and Public Health, Yale University, New Haven, CT). Although Upjohn provided the supplies of their already marketed MP formulation (Solu Medrol) and the aqueous vehicle (placebo) in support of NASCIS I and II, the trials were funded solely with peer-reviewed grant support from the NINDS. NASCIS III was also NIH-supported although Upjohn, in addition to providing MP at no cost, shouldered some of the monitoring costs relevant to tirilazad which was still under premarketing clinical development. However, the clinical data analysis was carried out at Yale University, completely independent of The Upjohn Company.

Following the demonstration of the efficacy of the 24-h MP dosing regimen in NASCIS II, Upjohn successfully achieved registration of the drug for use in acute SCI in Canada, several western European countries and most Far Eastern countries where the drug was already marketed for anti-inflammatory uses in the early 1990s. However, due to the FDA requirement for two wellcontrolled clinical trials, which both demonstrated substantial evidence of efficacy, the submission of a New Drug Application (NDA) for use in SCI was not possible on the strength of NASCIS II alone. Nevertheless, due to the fact that MP was already marketed in the U.S. for several therapeutic indications, its extensive use in human SCI (albeit unapproved) was possible even though The Upjohn Company could not openly promote it for the SCI indication. Furthermore, because SCI represented an unmet medical need, the 24-h NASCIS II MP dosing protocol quickly became the de facto, albeit unofficial, standard of care for human SCI in the U.S. as well as in other countries in which it was registered for SCI.

Subsequent to NASCIS II, two other groups of investigators in Japan ${ }^{99}$ and France ${ }^{100}$ reported successful replications of the therapeutic efficacy of the NASCIS II MP protocol in SCI patients. However, Upjohn, after becom- 
ing Pharmacia \& Upjohn in 1995, still elected to not file an NDA even though the requirement for two successful trials had seemingly been met. This decision to not seek U.S. registration for acute SCI was based upon the fact that the drug was already widely used in the U.S. for acute SCI despite the absence of registration for that particular indication. In addition, the difficulties in successfully gathering up the necessary clinical data from non-company off-shore investigators made the pulling together of the required NDA documents exceedingly difficult. Thirdly, as recently reviewed by Bracken, ${ }^{63}$ there was reason to believe that these non-U.S. replications may not have been conducted in a rigorous enough manner to support FDA approval. For instance, in the Japanese trial, ${ }^{99}$ there was a differential loss to follow-up between the untreated and MP-treated patients, and it was not clear whether the French MP SCI trial was carried out in a rigorously blinded manner. ${ }^{100}$

From a regulatory standpoint, the NASCIS III trial did little to facilitate the potential registration filing of MP for SCI in the U.S. since it was not a placebo-controlled trial. In designing NASCIS III, the NASCIS clinical investigators concluded, on the basis of NASCIS II results showing significant efficacy of 24-h high-dose MP in comparison to placebo-treated patients, that it was no longer ethical to withhold high-dose MP from SCI victims. This trial design was reviewed and funded by the NINDS. Consequently, NASCIS III $^{59}$ became a comparison of 24-h vs. 48-h MP dosing and included a simultaneous comparison of the neurological outcome of patients treated with a single i.v. bolus of MP followed by $48 \mathrm{~h}$ of tirilazad dosing. Although the results showed that patients treated $>3 \mathrm{~h}$ post-injury did significantly better when dosed with MP for $48 \mathrm{~h}$ in comparison to only $24 \mathrm{~h}$ of treatment, the absence of a placebo left the placebocontrolled results of NASCIS II unconfirmed, except by the Japanese and French groups, whose trials may or may not have been as carefully conducted as the NASCIS trials. ${ }^{63}$

In the case of the MP bolus plus tirilazad group, those patients recovered as well as the 24-h and 48-h MPtreated patients when treatment was initiated within the first $3 \mathrm{~h}$, and between the 24- and 48-h MP groups in the 3- to 8-h treatment cohort. The neuroprotective performance of tirilazad was achieved even though the patient randomization resulted in the tirilazad study arm having a significantly lower mean motor entry score (i.e., on average the tirilazad treatment group showed evidence of more severe SCI-induced deficits before treatment). Nevertheless, even though these NASCIS III results suggest that the non-glucocorticoid steroid tirilazad may duplicate the neuroprotective efficacy of MP without the same side effects, the ultimate approval of this compound for $\mathrm{SCI}$ in humans requires at least another trial comparing it against placebo to have any hope of becoming registered by the FDA. Furthermore, a registration-worthy phase III trial of MP versus tirilazad is precluded by the fact that the comparator drug MP is not registered for SCI in the U.S.; phase III clinical trials destined for inclusion in NDAs cannot be conducted with one unapproved drug being compared to a second unapproved drug. Consequently, a scenario in which tirilazad could be successfully approved for SCI marketing in the U.S. is not apparent unless it were deemed ethically appropriate to test it against placebo (i.e., without MP).

At this point, GM-1 is not approved for any indication in the U.S., and to our knowledge is not approved for use in acute SCI in any country. In view of the lack of a significant improvement in a phase III trial in the degree of functional recovery seen in patients treated with MP plus GM-1 vs. patients receiving only MP, ${ }^{86,89,90}$ it is uncertain whether additional phase III trials will be attempted.

\section{FUTURE SCI DRUG DEVELOPMENT: PROBABLE NEED TO BUILD UPON HIGH-DOSE MP THERAPY}

At present, high-dose MP therapy, although not officially approved in the U.S. for acute SCI treatment, continues to be the unofficial U.S. standard of care as well as in most countries where MP is marketed. This appears to be the case even though some clinicians and clinical investigators believe that the NASCIS II and III trials are unconvincing, and that the risks high-dose MP therapy outweigh what are, on average, modest neurological benefits. ${ }^{92,94,101}$ In any event, it is likely that future trials of new drug treatments will have to be evaluated in addition to high-dose MP due to the apparent fact that the majority of clinicians who treat acute SCI patients are not prepared to withhold MP. The only situation in which this may be avoidable will be based upon preclinical studies showing that the neuroprotective effects of MP, and/or a second drug, are offset when the two are used simultaneously, or where there is a documented dangerous interaction of the two drugs. For instance, it has been reported that the coincident use of MP and the GM1 ganglioside in a preclinical SCI model resulted in an attenuation of the neuroprotective efficacy of MP and an increase in post-SCI mortality. ${ }^{102}$ Hence, the decision was made in the design of the phase III GM1 trial to not initiate the GM1 dosing until after the completion of the 24-h NASCIS II MP dosing protocol.

This future development scenario involving the necessary design of clinical trials where a second neuroprotective or neurorestorative drug is administered at the same time as, or in series with, high-dose MP, however, raises a significant challenge for both the sponsor of the new agent and for the FDA. From the perspective of the sponsor, there is the need to not only define the neuro- 
logical effects of the combination of the new compound with and without MP therapy, but also to carefully study toxicological and pharmacokinetic interactions of the two agents. From the vantage point of the FDA, the problem will exist of evaluating the effects of the combination of MP plus a second drug against MP, without ever having made the determination that MP, by itself, is better than placebo treatment. In other words, they will be evaluating one experimental drug against a combination of two experimental drugs. If there is any precedent for a solution to this regulatory situation, it will probably have to come from cancer chemotherapy drug review, where combination treatments are the norm.

\section{FUTURE NEUROPROTECTIVE PHARMACOLOGICAL APPROACHES}

Despite the pharmacological and regulatory difficulties of building additional neuroprotective strategies on top of high-dose MP, preclinical studies have provided several logical second-generation neuroprotective target mechanisms for pharmacological exploration in SCI models. Indeed, prototype pharmacological agents that target these mechanisms have been identified and tested in CNS injury models, showing promise for SCI therapy. The following discussion briefly reviews some of the leading neuroprotective approaches on the horizon.

\section{Novel antioxidant strategies that could replace high-dose MP}

In view of the clear role of reactive oxygen or oxygenradical-induced LP in the pathophysiology of post-traumatic spinal cord degeneration, and the demonstrated benefits of antioxidant compounds with neuroprotective activity like MP and tirilazad, it is logical to pursue the development of improved antioxidant compounds that could more safely and effectively inhibit post-traumatic LP compared to high-dose MP. Recent work suggests that the most critical ROS in acute SCI may be peroxynitrite, ${ }^{103,104}$ which is formed from the combination of superoxide and nitric oxide radicals. ${ }^{105,106}$ Peroxynitrite is capable of causing widespread damage to lipids, proteins, and nucleic acids. Prototypical scavengers of peroxynitrite include penicillamine and Tempol, both of which are neuroprotective in cell culture and in vivo models of acute CNS injury. ${ }^{107,108}$ Another promising antioxidant-based approach concerns the design of dualinhibitors of LP and neuronal nitric oxide synthase (an enzyme that contributes to the production of peroxynitrite). Such a dual-inhibitor compound, BN-80933, has been reported to attenuate post-traumatic and post-ischemic degeneration in in vivo models. ${ }^{109}$ Importantly, in comparison with a neuronal nitric oxide synthase inhibitor alone, BN-80933 has been shown to have superior neuroprotective efficacy.

\section{Anti-inflammatory strategies}

As discussed above in the context of the discussion of the possible anti-inflammatory mechanisms of action of MP, inflammatory processes play an important, although incompletely understood, role in the pathophysiology of acute SCI. Understanding this role is complicated by the observations that while some aspects of post-traumatic inflammation in the spinal cord are clearly detrimental, other delayed inflammatory aspects may facilitate repair mechanisms. ${ }^{52}$ In regards to the negative aspects of inflammation in the injured cord, the best-developed therapeutic approach has been aimed at the observation that COX2 activation is involved in the secondary injury process (FIG. 1) and that inhibitors of COX2 are neuroprotective and enhance neurological recovery in animal models of SCI. ${ }^{110-114}$ Considering the fact that multiple COX2 inhibitors (rofecoxib, celecoxib) have been approved for certain rheumatic inflammatory conditions in the U.S. and most countries, the potential application of one of these to acute SCI therapy should probably be pursued. However, at present parenteral formulations for i.v. use have not been marketed.

\section{Role of calpain in acute SCI and potential neuroprotective efficacy of calpain inhibitors}

A very strong candidate mechanism for neuroprotective intervention is the calcium-activated enzyme calpain. ${ }^{115,116}$ Multiple laboratories and studies have demonstrated an important role of calpain activation in mediating post-traumatic axonal damage in acute SCI models. ${ }^{117-124}$ Several of these studies have reported neuroprotective efficacy of prototype calpain inhibitors. However, the translation of calpain inhibition into neuroprotective clinical trials has been precluded by the lack of small molecule inhibitors with sufficient CNS penetration and appropriate pharmaceutical and pharmacokinetic properties. Hopefully, these limitations will be overcome with future inhibitors in view of the clear role of calpain in SCI pathophysiology.

\section{Thyrotropin-releasing hormone and TRH analogs}

As discussed above, the opiate receptor antagonist naloxone was shown many years ago to be neuroprotective in models of acute $\mathrm{SCI}^{40,41}$ and showed evidence of some efficacy in the NASCIS II trial. ${ }^{46}$ This has been interpreted as an indication that opiate receptor mechanisms are involved in the acute pathophysiology of SCI. Another opiate receptor antagonist approach that has been intensively explored concerns the use of thyrotropin-releasing hormone (TRH) which can act as a physiological antagonist of opiate receptor activation by injury-induced endorphin release. ${ }^{9}$ TRH administration has been shown to improve neurological recovery in cats $^{125}$ and rats, ${ }^{126}$ and has been preliminarily tested in a phase II safety trial in a small number of SCI patients. ${ }^{127}$ Based upon the knowledge that TRH may possess mul- 
tiple neuroprotective actions, several TRH analogs with improved pharmaceutical and brain penetration properties have been discovered and are actively being evaluated for possible entry into future SCI trials. ${ }^{126,128,129}$

\section{Role of apoptosis in acute SCI and anti-apoptotic therapeutic strategies}

A potentially promising area of neuroprotective drug discovery for treating acute SCI is the development of agents targeting apoptotic cell death. Several of the intracellular biochemical steps involved in apoptosis are common across species, and this has led to a better appreciation of the biological significance of this cell death process. Apoptosis has long been considered as an essential mechanism for eliminating redundant cells during CNS development. However, a number of recent studies have documented that apoptosis is emerging as a critical factor contributing to ongoing cell loss following traumatic CNS injury, especially in SCI. Apoptotic cell death can be detected hours to several weeks following SCI and occurs in numerous cell types, including neurons, oligodendroglia, and inflammatory cells such as neutrophils, microglia, and macrophages. ${ }^{130-137}$ In spite of these observations, the role of apoptosis as a contributing factor in limiting functional recovery has not been well established. This issue can only be addressed by elucidating the extracellular and intracellular signaling events regulating this cell death process. Understanding these signaling events is the first step in developing effective therapeutic agents targeting different steps in the apoptotic cascade.

\section{The caspase-3 apoptotic cascade}

While the extracellular signaling events leading to apoptosis in SCI are not entirely clear, it has been suggested that the intracellular apoptotic cascade leads to a common endpoint, i.e., the activation of the cysteine protease caspase-3. ${ }^{130,132,138-142}$ Additional studies have reported evidence of caspase-3 activation in other types of CNS injury models including head trauma and ischemia/stroke. ${ }^{143-152}$ The biochemical pathway(s) leading to caspase-3 activation have been extensively studied using in vitro models of apoptotic cell death, and it has been well documented that the mitochondria are thought to play a critical, if not essential role in activation of caspase-3. As shown in FIG. 4, apoptotic signals reaching the mitochondria results in the release of cytochrome $c$ and Smac/DIABLO. ${ }^{153-157}$ Cytochrome $c$ then interacts with Apaf-1 (apoptosis protease activating factor-1) to promote the activation of caspase- 9 , an upstream activator of caspase-3. Smac/DIABLO has been shown to promote capsase- 9 and caspase- 3 activation by removing the inhibitory influence of members of the inhibitor of apoptotic proteins (IAPs) family. ${ }^{154,157-162}$ In addition, the mitochondria can also release pro-apoptotic molecules such as endonuclease $\mathrm{G}$ and apoptosis-inducing factor (AIF), which are thought to function independent of caspase activation. ${ }^{163-168}$ Therefore, a number of signaling events associated with the mitochondria are thought to regulate activation of a caspase-dependent and caspase-independent apoptotic cell death program. Targeting these signaling events at the level of the mitochondria, as well as apoptotic signals upstream of the mitochondria, will be essential for determining the contribution of this cell death process to neurological dysfunction in SCI.

\section{Extracellular signals of apoptosis in SCI}

To date, it is evident that a clear understanding of the extracellular events leading to transduction of an apoptotic signal in SCI is lacking. This is an important area of research, because inhibiting the extracellular signals as far upstream as possible should limit apoptosis following SCI to a greater degree than targeting the intracellular pathway(s). A number of studies have implicated several potential candidate molecules as extracellular apoptotic signals in SCI, including pro-inflammatory cytokines, certain growth factors, Fas ligand, and glutamate, to name a few. In addition, there is evidence that ROS, such as superoxide radical and peroxynitrite, which are produced in the injured spinal cord, can also lead to apoptosis. What is clear from this limited list is that although caspase- 3 can be considered as the common endpoint in the apoptotic biochemical cascade, there are a number of extracellular signals that could contribute to transduction of the apoptotic signal. Therefore, it will be important to determine the contribution of each of these different extracellular events to the overall apoptotic cell loss that occurs in SCI.

As described above, several studies have demonstrated that the spinal cord contains the molecular machinery necessary for activation and execution of the caspase- 3 apoptotic pathway. However, the role of apoptosis in SCI is not clear and this is based, in part, on the lack of effective treatment strategies that block or inhibit the caspase-3 apoptotic cascade. More importantly, identifying which step(s) to target in the biochemical cascade may be one of the most critical issues affecting translational research efforts. Existing strategies are based primarily on the use of competitive caspase inhibitors containing tri- and tetrapeptide amino acid sequences that are preferred substrates of certain caspases. While these inhibitors have been modified to increase cell permeability and reduce inactivation, evidence of their efficacy has been limited primarily to in vitro studies. Only a few studies report the effective use of these compounds in models of CNS injury, ${ }^{140,143,144,148,149}$ although one study has reported no supporting evidence of reduced caspase activity when a broad-acting caspase inhibitor is delivered to the injured spinal cord. ${ }^{168}$ The relative paucity of positive results in vivo may be related to the 


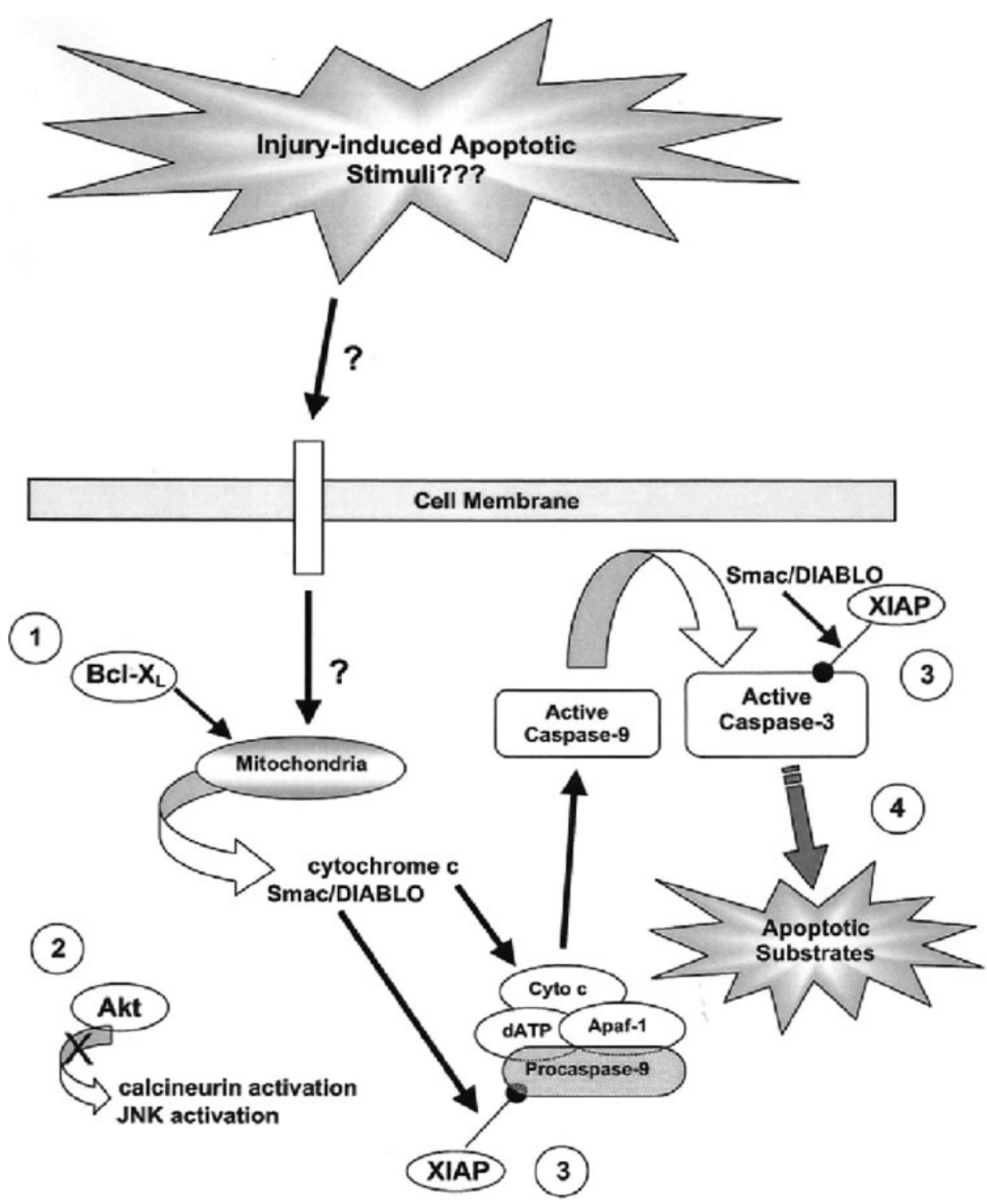

FIG. 4. Schematic diagram depicting the potential steps leading to caspase-3 activation in CNS trauma. Several injury-induced extracellular apoptotic stimuli most likely exist and the mechanisms by which these extracellular signals are transduced to the intracellular pathway are only beginning to emerge. However, there are several lines of evidence supporting the release of pro-apoptotic molecules from the mitochondria as important steps in activation of the caspase-3 apoptotic. Other pro-apoptotic factors that are released by the mitochondria, but do not involve caspase-3 activation include endonuclease $\mathrm{G}$ and AIF (not shown). Given our current understanding of the intracellular signaling events, there are a number of points in the apoptotic cascade that can be targeted. For example, the overexpression of anti-apoptotic molecules including $\mathrm{Bcl}-\mathrm{X}_{\mathrm{L}},{ }^{1} \mathrm{Akt}^{2}{ }^{2}$ and $\mathrm{XIAP}^{3}$ to the injured spinal cord may limit ongoing apoptosis by reducing cytochrome $c$ release $\left(B c l-X_{L}\right.$ and $\left.A k t\right)$, the activation of calcineurin and the JNK stress-induced pathway (Akt), or caspase activation via Smac/DIABLO (XIAP). In addition, the identification of small, cell-permeable synthetic molecules that inhibit the actions or activation of caspase- $3^{4}$ may prove advantageous over existing tri- and tetrapeptide-based competitive inhibitors. Such strategies will be critical for understanding the contribution of apoptotic cell death to the functional deficits observed in SCl, and hopefully allow for development of therapeutic approaches targeting this cell death process.

biochemical properties of these inhibitors. For example, the delivery of sufficient levels of the inhibitors to the cells of interest over a broad time-window and to areas distant to the site of injury may be very limited. In addition, the half-life of these peptide-based compounds, such as the caspase-3 inhibitor z-DEVD-fmk, may reduce their effective concentration. While the half-life of such inhibitors has not been thoroughly examined in SCI, the presence of numerous proteases released in the injured spinal cord could certainly limit the concentration of the intact peptide that ultimately crosses the cell membrane. Given these caveats, alternative strategies targeting different steps in the intracellular apoptotic cascade, and caspase-3 in particular, need to be considered. 


\section{Therapeutic interventions: delivery of anti-apoptotic} genes to the injured CNS

We have been able to uncover, in a relatively short period of time, a number of basic principles about apoptotic cell death associated with traumatic SCI. The rapid onset of caspase-3 activation in some injury models indicates that there is a relatively narrow therapeutic timewindow for implementing treatments targeting caspase-3 activation. However, apoptosis does persist for some time following SCI, and strategies targeting caspase-3 activation and enzyme activity may prove beneficial in minimizing the cleavage of substrates involved in generating the apoptotic phenotype.

One approach is the use of retroviral vectors to deliver anti-apoptotic genes to the injured spinal cord. Adenoviruses generally exhibit short-term expression of the gene of interest (typically 4 to 6 weeks) due to nonintegration into the host genome. However, transient expression would be considered optimal in CNS injury as apoptosis is thought to range from hours to weeks following the initial insult, as is the case in SCI. ${ }^{131,133,135}$ Therefore, expression of the anti-apoptotic gene would not be required at extended time points when apoptosis is no longer a predominant event in the injured spinal cord. One major caveat with using adenoviral vectors is the prevalence of white matter cytotoxicity, observed when high titers are injected into the spinal cord. This can be alleviated to some extent with immunosuppression; however, immunosuppressive treatment may yield inconclusive results or confound interpretation of any positive outcome. Other gene delivery strategies, which would limit cytotoxicity and result in more widespread dispersion and transfection of larger areas of tissue, should be considered.

The genes of interest to be delivered to the injured CNS are based on their potential to inhibit different steps in the caspase-3-mediated apoptotic cascade. Akt (or protein kinase B) is a serine/threonine kinase that regulates anti-apoptotic signals, in part, through activation of phosphoinositide 3-kinase, or PI3-kinase. ${ }^{169-174}$ Overexpression of Akt prevents apoptosis in neurons and other cells following withdrawal of serum or growth factors. ${ }^{170,171,175-179}$ The activation of Akt appears to require translocation to lipid membranes to interact with downstream lipid products of PI3-kinase. This observation led to the development of constitutively active Akt via N-terminal myristolation, which promotes translocation of Akt to membranes. Therefore, gene transfer of activated Akt to the injured spinal cord may prove beneficial in reducing activation of the apoptotic cascade. The ability of Akt to inhibit apoptosis may be related to activation of the JNK stress-induced apoptotic cascade and/or intracellular events upstream to the mitochondrial release of cytochrome $c$ and possibly Smac/DIABLO. A similar argument could be made for overexpressing Bcl-
$\mathrm{X}_{\mathrm{L}}$, an anti-apoptotic member of the Bcl-2 gene family that binds to and inhibits the actions of other pro-apoptotic Bcl-2 family members.

Another step to target in the caspase-3 apoptotic cascade involves events upstream of caspase- 3 but downstream of mitochondrial events. This would involve the overexpression of members of the IAP family. ${ }^{159,180-183}$ The first IAP family member identified was p35, a baculoviral protein that suppresses apoptosis in a number of cell types and under a variety of conditions. Additional studies demonstrated that several IAPs exist in Drosoph$i l a$ and function by binding to the inactive pro-caspase and, as a result, inhibit the processing of the zymogen to the active form. ${ }^{184,185}$ Mammalian IAPs include XIAP, c-IAP1, c-IAP2, NAIP, and survivin, although XIAP inhibits caspase- 3 activation at a $K_{i}$ that is much lower compared to any of the other IAPs. The removal of XIAP inhibition is thought to be dependent on Smac/DIABLO when released by the mitochondria possibly along with cytochrome $c .^{154,157}$ Smac/DIABLO has been shown to displace XIAP from caspase-9, allowing the latter to be activated through its interactions with Apaf-1, and can also remove XIAP directly from caspase-3. Taken together, these studies suggest that overexpression of IAPs such as XIAP and possibly p35, which is a broad caspase inhibitor, should reduce caspase-3 activation in cells following CNS injury.

\section{Discovery and development of inhibitory mimetics (pros and cons)}

An additional treatment strategy that has great potential is the identification of small, cell-permeable, organicbased molecules that block or inhibit the actions of caspase-3. Understanding the tertiary structure of critical sites (e.g., binding domains, active site, etc.) has and will allow for structure-based drug design of non-peptidic molecules. X-ray crystallography and computer-based molecular modeling has led to the development of highly selective caspase- 3 inhibitors with $K_{i}$ values reaching $20 \mathrm{~nm}$. In addition, using a structure-based combinatorial array design, Head et al. ${ }^{186}$ reported the co-crystallization of caspase-3 and a non-peptidic thiomethylketone compound that inhibits the actions of activated caspase-3. The ability to identify and design cell-permeable analogs of these potent and highly selective non-peptide-based inhibitors of caspase-3 may prove more beneficial for in vivo applications than existing inhibitors, such as tri- and tetrapeptidebased molecules, which are relatively limited in their in vivo efficacy. Although these studies have focused on inhibitors targeting caspase- 3 , analogous strategies have been used to identify specific regions of XIAP that interact with and inhibit the activation of caspase-9. Therefore, it is conceivable that developing non-peptidic-based synthetic compounds that mimic the actions of XIAP will allow for the targeting of steps upstream to caspase-3 activation. 


\section{Apoptosis and SCI: conclusions}

Apoptotic cell death is a well-described but poorly understood process in acute SCI. Interestingly, the delayed onset of apoptosis in oligodendroglia distant to the site of injury appears to be unique to SCI, and has important therapeutic implications. Specifically, oligodendroglial apoptosis has been proposed to contribute to axonal demyelination and dysfunction in areas distant to the injury epicenter, which may contribute further to long-term neurological deficits. These observations point to the need for a better understanding of the role of apoptosis in SCI, and the development of treatment strategies that are highly selective and directed to specific steps in the apoptotic cascade.

\section{SUMMARY}

The pathophysiology of acute SCI involves a complex cascade of secondary neurodegenerative events that are set in motion by the primary injury. This cascade includes molecular events that are often referred to as necrotic and apoptotic. The increasingly successful definition of the SCI secondary injury process led to the pursuit of a number of pharmacological neuroprotective strategies which have been shown to interrupt the secondary injury process at selected points and to improve neurological recovery in acute SCI animal models. Four of these agents, the glucocorticoid steroid MP, the opiate receptor antagonist naloxone, the non-glucocorticoid 21aminosteroid tirilazad, and the monosialoganglioside GM1 have been examined in phase III clinical trials in SCI patients, and in all cases the trial results show some evidence of benefit although in all cases the effects appear to be modest. Most convincing has been the NASCIS trials, which have demonstrated the efficacy of highdose MP if begun within the first $8 \mathrm{~h}$ after injury. Although the use of MP and the NASCIS trial design and statistical analysis has sparked intense criticisms and debate, the majority of clinicians who treat SCI believe that MP has value and should be employed. In the opinion of the present authors, the magnitude of these neuroprotective, and in the case of GM-1, neurorestorative effects is at least sufficient to validate the concept of acute pharmacotherapy for SCI and to inspire continued efforts to discover and develop improved therapies. The neuroprotective mechanism of MP is believed to be primarily inhibition of post-traumatic LP, although anti-inflammatory effects may play some role as well. As a result, the continued search for safer and more effective LP-inhibitory (antioxidant) agents seems warranted. This view is supported by the apparent efficacy of tirilazad in NASCIS III. One approach would be to scavenge peroxynitrite which may be the preeminent ROS involved in secondary injury; however, several other promising nonantioxidant approaches could either replace or be built upon MP or tirilazad. These include multi-mechanistic TRH analogs, COX 2 inhibitors and other anti-inflammatory strategies, inhibitors of calpain and inhibitors of the complex apoptotic cascade that is largely responsible for delayed degeneration of neural and glial elements in the injured cord. Although the design of future clinical trials will, of necessity, be complex, the devastating consequences of SCI to the patient, his/her family, and society strongly support our continued efforts to develop safe and effective neuroprotective therapies that will lessen secondary injury and result in clinically significant neurological recovery.

\section{REFERENCES}

1. Anderson DK, Hall ED. Pathophysiology of spinal cord trauma. Ann Emerg Med 22:987-992, 1993.

2. Hall ED. Mechanisms of secondary CNS injury. In: Neurosurgery 96: manual of neurosurgery (Palmer JD, ed), pp 505-510. New York: Churchill-Livingstone, 1996.

3. Hall ED, Braughler JM. Central nervous system trauma and stroke. II. Physiological and pharmacological evidence for involvement of oxygen radicals and lipid peroxidation. Free Radic Biol Med 6:303-313, 1989.

4. Tator $\mathrm{CH}$, Fehlings MG. Review of the secondary injury theory of acute spinal cord trauma with emphasis on vascular mechanisms. $J$ Neurosurg 75:15-26, 1991.

5. Faden AI. Therapeutic approaches to spinal cord injury. $A d v$ Neurol 72:377-386, 1997.

6. Faden AI, Salzman S. Pharmacological strategies in CNS trauma. Trends Pharmacol Sci 13:29-35, 1992.

7. Braughler JM, Hall ED. Central nervous system trauma and stroke. I. Biochemical considerations for oxygen radical formation and lipid peroxidation. Free Radic Biol Med 6:289-301, 1989.

8. Hall ED, Braughler JM. Free radicals in CNS injury. Res Publ Assoc Res Nerv Ment Dis 71:81-105, 1993.

9. Faden AI, Holaday JW. A role for endorphins in the pathophysiology of spinal cord injury. Adv Biochem Psychopharmacol 28: 435-446, 1981.

10. Reulen HJ, Schurmann K. Steroids and brain edema. Berlin: Springer, 1972.

11. Bracken MB, Collins WF, Freeman DF, Shepard MJ, Silten RM, Hellenbrand KG et al. Efficacy of methylprednisolone in acute spinal cord injury. JAMA 51:45-52, 1984.

12. Bracken MB, Shepard MJ, Hellenbrand KG, Collins WF, LeoSummers L, Freeman DF et al. Methylprednisolone and neurological function 1 year after spinal cord injury. Results of the National Acute Spinal Cord Injury Study. J Neurosurg 63:704713, 1985.

13. Demopoulos HB, Flamm ES, Pietronigro DD, Seligman ML. The free radical pathology and the microcirculation in the major central nervous system disorders. Acta Physiol Scand Suppl 492:91$119,1980$.

14. Hall ED. The neuroprotective pharmacology of methylprednisolone. J Neurosurg 76:13-22, 1992.

15. Hall ED, Braughler JM. Acute effects of intravenous glucocorticoid pretreatment on the in vitro peroxidation of cat spinal cord tissue. Exp Neurol 73:321-324, 1981.

16. Hall ED, Braughler JM. Glucocorticoid mechanisms in acute spinal cord injury: a review and therapeutic rationale. Surg Neurol 18:320-327, 1982.

17. Hall ED. Glucocorticoid effects on central nervous excitability and synaptic transmission. Int Rev Neurobiol 23:165-195, 1982.

18. Hall ED, Wolf DL, Braughler JM. Effects of a single large dose of methylprednisolone sodium succinate on experimental posttraumatic spinal cord ischemia: dose-response and time-action analysis. J Neurosurg 61:124-130, 1984. 
19. Young W, Flamm ES. Effect of high-dose corticosteroid therapy on blood flow, evoked potentials, and extracellular calcium in experimental spinal injury. J Neurosurg 57:667-673, 1982.

20. Anderson DK, Means ED, Waters TR, Green ES. Microvascular perfusion and metabolism in injured spinal cord after methylprednisolone treatment. J Neurosurg 56:106-113, 1982.

21. Braughler JM, Hall ED. Lactate and pyruvate metabolism in injured cat spinal cord before and after a single large intravenous dose of methylprednisolone. J Neurosurg 59:256-261, 1983.

22. Braughler JM, Hall ED. Effects of multi-dose methylprednisolone sodium succinate administration on injured cat spinal cord neurofilament degradation and energy metabolism. $J \mathrm{Neu}$ rosurg 61:290-295, 1984.

23. Braughler JM, Hall ED. Correlation of methylprednisolone levels in cat spinal cord with its effects on $(\mathrm{Na}++\mathrm{K}+)$-ATPase, lipid peroxidation, and alpha motor neuron function. $J$ Neurosurg 56 : $838-844,1982$.

24. Braughler JM, Hall ED. Uptake and elimination of methylprednisolone from contused cat spinal cord following intravenous injection of the sodium succinate ester. $J$ Neurosurg 58:538-542, 1983.

25. Anderson DK, Saunders RD, Demediuk P et al. Lipid hydrolysis and peroxidation in injured spinal cord: partial protection with methylprednisolone or vitamin E and selenium. Cent Nerv Syst Trauma 2:257-267, 1985.

26. Braughler JM, Hall ED, Means ED, Waters TR, Anderson DK. Evaluation of an intensive methylprednisolone sodium succinate dosing regimen in experimental spinal cord injury. $J$ Neurosurg 67:102-105, 1987.

27. Taoka Y, Okajima K, Uchiba M, Johno M. Methylprednisolone reduces spinal cord injury in rats without affecting tumor necrosis factor- $\alpha$ production. J Neurotrauma 18:533-543, 2001.

28. Farooque M, Hillered L, Holtz A, Olsson Y. Effects of methylprednisolone on extracellular lactic acidosis and amino acids after severe compression injury of rat spinal cord. $J$ Neurochem 66: 1125-1130, 1996.

29. Holtz A, Nystrom B, Gerdin B. Effect of methylprednisolone on motor function and spinal cord blood flow after spinal cord compression in rats. Acta Neurol Scand 82:68-73, 1990.

30. Xu J, Qu ZX, Hogan EL, Perot PL Jr. Protective effect of methylprednisolone on vascular injury in rat spinal cord injury. $J \mathrm{Neu}$ rotrauma 9:245-253, 1992.

31. Xu J, Kim GM, Ahmed SH, Yan P, Xu XM, Hsu CY. Glucocorticoid receptor-mediated suppression of activator protein-1 activation and matrix metalloproteinase expression after spinal cord injury. J Neurosci 21:92-97, 2001.

32. Behrmann DL, Bresnahan JC, Beattie MS. Modeling of acute spinal cord injury in the rat: neuroprotection and enhanced recovery with methylprednisolone, U-74006F and YM-14673. Exp Neurol 126:61-75, 1994.

33. Koyanagi I, Tator $\mathrm{CH}$. Effect of a single huge dose of methylprednisolone on blood flow, evoked potentials, and histology after acute spinal cord injury in the rat. Neurol Res 19:289-299, 1997.

34. Rabchevsky AG, Fugaccia I, Sullivan PG, Blades DA, Scheff SW. Efficacy of methylprednisolone therapy for the injured rat spinal cord. J Neurosci Res 68:7-18, 2002.

35. Schimmer BP, Parker KL. Adrenocorticotropic hormone; adrenocortical steroids and their synthetic analogs; inhibitors of the synthesis and actions of adrenocortical hormones. In: The pharmacological basis of therapeutics, Ed 10 (Hardman JG, Limberd LE, Gilman, AG, eds), pp 1649-1677. New York: McGraw-Hill, 2001.

36. Hall ED, McCall JM, Chase RL, Yonkers PA, Braughler JM. A nonglucocorticoid steroid analog of methylprednisolone duplicates its high-dose pharmacology in models of central nervous system trauma and neuronal membrane damage. $J$ Pharmacol Exp Ther 242:137-142, 1987.

37. Braughler JM. Lipid peroxidation-induced inhibition of gammaaminobutyric acid uptake in rat brain synaptosomes: protection by glucocorticoids. $J$ Neurochem 44:1282-1288, 1985.
38. Holaday JW, Faden AI. Naloxone reverses the pathophysiology of shock through an antagonism of endorphin systems. Adv Biochem Psychopharmacol 28:421-434, 1981.

39. Holaday JW, Faden AI. Naloxone treatment in shock. Lancet 2:201, 1981.

40. Flamm ES, Young W, Demopoulos HB, DeCrescito V, Tomasula JJ. Experimental spinal cord injury: treatment with naloxone. Neurosurgery 10:227-231, 1982.

41. Faden AI, Jacobs TP, Holaday JW. Opiate antagonist improves neurologic recovery after spinal injury. Science 211:493-494, 1981.

42. Faden AI, Jacobs TP, Holaday JW. Comparison of early and late naloxone treatment in experimental spinal injury. Neurology 32 677-681, 1982.

43. Flamm ES, Young W, Collins WF, Piepmeier J, Clifton GL, Fischer B. A phase I trial of naloxone treatment in acute spinal cord injury. J Neurosurg 63:390-397, 1985.

44. Bracken MB, Shepard MJ, Collins WF et al. A randomized, controlled trial of methylprednisolone or naloxone in the treatment of acute spinal-cord injury. Results of the Second National Acute Spinal Cord Injury Study. N Engl J Med 322:1405-1411, 1990.

45. Bracken MB, Shepard MJ, Collins WF Jr et al. Methylprednisolone or naloxone treatment after acute spinal cord injury: 1-year follow-up data. Results of the second National Acute Spinal Cord Injury Study. J Neurosurg 76:23-31, 1992.

46. Bracken MB, Holford TR. Effects of timing of methylprednisolone or naloxone administration on recovery of segmental and long-tract neurological function in NASCIS 2. J Neurosurg 79: 500-507, 1993.

47. Bracken MB. Pharmacological treatment of acute spinal cord injury: current status and future projects. J Emerg Med 11[Suppl 1]:43-48, 1993

48. Anderson DK, Saunders RD, Demediuk P, Dugan LL, Braughler JM, Hall ED. Lipid hydrolysis and peroxidation in injured spinal cord: partial protection with methylprednisolone or vitamin $\mathrm{E}$ and selenium. CNS Trauma 2:257-268, 1986.

49. Clark CR, Maclusky NJ, Naftolin F. Glucocorticoid receptors in the spinal cord. Brain Res 217:412-415, 1981.

50. Hall ED, Yonkers PA, Taylor BM, Sun FF. Lack of effect of postinjury treatment with methylprednisolone or tirilazad mesylate on the increase in eicosanoid levels in the acutely injured cat spinal cord. J Neurotrauma 12:245-256, 1995.

51. Bartholdi D, Schwab ME. Methylprednisolone inhibits early inflammatory processes but not ischemic cell death after experimental spinal cord lesion in the rat. Brain Res 672:177-186, 1995.

52. Popovich PG, Jones TB. Manipulating neuroinflammatory reactions in the injured spinal cord: back to basics. Trends Pharmacol Sci 24:13-17, 2003.

53. Popovich PG, Wei P, Stokes BT. Cellular inflammatory response after spinal cord injury in Sprague-Dawley and Lewis rats. J Comp Neurol 377:443-464, 1997.

54. Popovich PG, Stokes BT, Whitacre CC. Concept of autoimmunity following spinal cord injury: possible roles for $\mathrm{T}$ lymphocytes in the traumatized central nervous system. $J$ Neurosci Res 45:349-363, 1996

55. Popovich PG, Yu JY, Whitacre CC. Spinal cord neuropathology in rat experimental autoimmune encephalomyelitis: modulation by oral administration of myelin basic protein. J Neuropathol Exp Neurol 56:1323-1338, 1997.

56. Hall ED. Lazaroid: mechanisms of action and implications for disorders of the CNS. Neuroscientist 3:42-51, 1997.

57. Hall ED, McCall JM, Means ED. Therapeutic potential of the lazaroids (21-aminosteroids) in acute central nervous system trauma, ischemia and subarachnoid hemorrhage. Adv Pharmacol 28:221-268, 1994.

58. Braughler JM, Chase RL, Neff GL, Yonkers PA, Day JS, Hall ED et al. A new 21-aminosteroid antioxidant lacking glucocorticoid activity stimulates adrenocorticotropin secretion and blocks arachidonic acid release from mouse pituitary tumor (AtT-20) cells. J Pharmacol Exp Ther 244:423-427, 1988.

59. Bracken MB, Shepard MJ, Holford TR, Leo-Summers L, Aldrich 
EF, Fazi M et al. Administration of methylprednisolone for 24 or 48 hours or tirilazad mesylate for 48 hours in the treatment of acute spinal cord injury. Results of the Third National Acute Spinal Cord Injury Randomized Controlled Trial. JAMA 77:1597-1604, 1997.

60. Bracken MB, Shepard MJ, Holford TR, Leo-Summers L, Aldrich $\mathrm{EF}$, Fazi $\mathrm{M}$ et al. Methylprednisolone or tirilazad mesylate administration after acute spinal cord injury: 1-year follow up. Results of the Third National Acute Spinal Cord Injury Randomized Controlled Trial. J Neurosurg 89:699-706, 1998.

61. Galandiuk S, Raque G, Appel S, Polk HC Jr. The two-edged sword of large-dose steroids for spinal cord trauma. Ann Surg 218:419-427, 1993.

62. Del Rosario Molano M, Broton JG, Bean JA, Calancie B. Complications associated with the prophylactic use of methylprednisolone during surgical stabilization after spinal cord injury. J Neurosurg 96[Suppl 3]:267-272, 2002.

63. Bracken MB. Methylprednisolone and acute spinal cord injury: an update of the randomized evidence. Spine 26[Suppl 24]:47-54, 2001.

64. Scheff SW, Benardo LS, Cotman CW. Hydrocortison administration retards axon sprouting in the rat dentate gyrus. Exp Neurol 68:195-201, 1980.

65. Scheff SW, Cotman CW. Chronic glucocorticoid therapy alters axon sprouting in the hippocampal dentate gyrus. Exp Neurol 76:644-654, 1982.

66. Scheff SW, DeKosky ST. Steroid suppression of axon sprouting in the hippocampal dentate gyrus of the adult rat: dose-response relationship. Exp Neurol 82:183-191, 1983.

67. Scheff SW, Dekosky ST. Glucocorticoid suppression of lesioninduced synaptogenesis: effect of temporal manipulation of steroid treatment. Exp Neurol 105:260-264, 1989.

68. Sapolsky RM. Glucocorticoid toxicity in the hippocampus: temporal aspects of neuronal vulnerability. Brain Res 359:300-305, 1985.

69. Sapolsky RM, Krey LC, McEwen BS. The neuroendocrinology of stress and aging: the glucocorticoid cascade hypothesis. Endocr Rev 7:284-301, 1986.

70. McIntosh LJ, Sapolsky RM. Glucocorticoids may enhance oxygen radical-mediated neurotoxicity. Neurotoxicology 17:873-882, 1996.

71. Landfield PW, Eldridge JC. The glucocorticoid hypothesis of age-related hippocampal neurodegeneration: role of dysregulated intraneuronal calcium. Ann NY Acad Sci 746:308-326, 1994.

72. Elliott EM, Sapolsky RM. Corticosterone enhances kainic acidinduced calcium elevation in cultured hippocampal neurons. J Neurochem 59:1033-1040, 1992.

73. Dinkel K, MacPherson A, Sapolsky RM. Novel glucocorticoid effects on acute inflammation in the CNS. J Neurochem 84:705716, 2003.

74. Morse JK, Davis JN. Regulation of ischemic hippocampal damage in the gerbil: adrenalectomy alters the rate of CA1 cell disappearance. Exp Neurol 110:86-92, 1990.

75. Shin CY, Choi JW, Jang ES, Ryu JH, Kim WK, Kim HC et al. Glucocorticoids exacerbate peroxynitrite mediated potentiation of glucose deprivation-induced death of rat primary astrocytes. Brain Res 923:163-171, 2001.

76. Stein-Behrens BA, Elliott EM, Miller CA, Schilling JW, Newcombe R, Sapolsky RM. Glucocorticoids exacerbate kainic acidinduced extracellular accumulation of excitatory amino acids in the rat hippocampus. J Neurochem 58:1730-1735, 1992.

77. Oudega M, Vargas CG, Weber AB, Kleitman N, Bunge MB. Long-term effects of methylprednisolone following transection of adult rat spinal cord. Eur J Neurosci 11:2453-2464, 1999.

78. Chen A, Xu XM, Kleitman N, Bunge MB. Methylprednisolone administration improves axonal regeneration into Schwann cell grafts in transected adult rat thoracic spinal cord. Exp Neurol 138:261-276, 1996.

79. Li X, Oudega M, Dancausse HA, Levi AD. The effect of methylprednisolone on caspase- 3 activation after rat spinal cord transection. Restor Neurol Neurosci 17:203-209, 2000.

80. Ray SK, Wilford GG, Matzelle DC, Hogan EL, Banik NL. Cal- peptin and methylprednisolone inhibit apoptosis in rat spinal cord injury. Ann NY Acad Sci 890:261-269, 1999.

81. Kanellopoulos GK, Kato H, Wu Y, Dougenis D, Mackey M, Hsu CY et al. Neuronal cell death in the ischemic spinal cord: the effect of methylprednisolone. Ann Thorac Surg 64:1279-1286, 1997.

82. Diem R, Hobom M, Maier K, Weissert R, Storch MK, Meyer R et al. Methylprednisolone increases neuronal apoptosis during autoimmune CNS inflammation by inhibition of an endogenous neuroprotective pathway. J Neurosci 23:6993-7000, 2003.

83. Gorio A. Ganglioside enhancement of neuronal differentiation, plasticity, and repair. CRC Crit Rev Clin Neurobiol 2:241-296, 1986.

84. Gorio A, Vitadello M. Ganglioside prevention of neuronal functional decay. Prog Brain Res 71:203-208, 1987.

85. Gorio A. Gangliosides as a possible treatment affecting neuronal repair processes. Adv Neurol 47:523-530, 1988.

86. Geisler FH, Coleman WP, Grieco G, Poonian D. The Sygen multicenter acute spinal cord injury study. Spine 26[Suppl 24]: 87-98, 2001.

87. Geisler FH, Dorsey FC, Coleman WP. GM1 gangliosides in the treatment of spinal cord injury: report of preliminary data analysis. Acta Neurobiol Exp (Warsz) 50:515-521, 1990.

88. Geisler FH, Dorsey FC, Coleman WP. Recovery of motor function after spinal-cord injury-a randomized, placebo-controlled trial with GM-1 ganglioside. $N$ Engl J Med 324:1829-1838, 1991.

89. Geisler FH, Coleman WP, Grieco G, Poonian D. Measurements and recovery patterns in a multicenter study of acute spinal cord injury. Spine 26[Suppl 24]:68-86, 2001.

90. Geisler FH, Coleman WP, Grieco G, Poonian D. Recruitment and early treatment in a multicenter study of acute spinal cord injury. Spine 26[Suppl 24]:58-67, 2001.

91. Bracken MB, Holford TR. Neurological and functional status 1 year after acute spinal cord injury: estimates of functional recovery in National Acute Spinal Cord Injury Study II from results modeled in National Acute Spinal Cord Injury Study III. $J$ Neurosurg 96[Suppl 3]:259-266, 2002.

92. Hurlbert RJ. Methylprednisolone for acute spinal cord injury: an inappropriate standard of care. J Neurosurg 93[Suppl 1]:1-7, 2000.

93. Short DJ, El Masry WS, Jones PW. High-dose methylprednisolone in the management of acute spinal cord injury-a systematic review from a clinical perspective. Spinal Cord 38:273286, 2000.

94. Coleman WP, Benzel D, Cahill DW, Ducker T, Geisler F, Green $\mathrm{B}$ et al. A critical appraisal of the reporting of the National Acute Spinal Cord Injury Studies (II and III) of methylprednisolone in acute spinal cord injury. J Spinal Disord 13:185-199, 2000.

95. Marler JR, Tilley BC, Lu M, Brott TG, Lyden PC, Grotta JC et al. Early stroke treatment associated with better outcome: the NINDS rt-PA stroke study. Neurology 55:1649-1655, 2000.

96. Kwiatkowski TG, Libman RB, Frankel M, Tilley BC, Morgenstern LB, Lu M et al. Effects of tissue plasminogen activator for acute ischemic stroke at one year. National Institute of Neurological Disorders and Stroke Recombinant Tissue Plasminogen Activator Stroke Study Group. N Engl J Med 340:1781-1787, 1999.

97. Fehlings MG. Summary statement: the use of methylprednisolone in acute spinal cord injury. Spine 26[Suppl 24:55, 2001.

98. Fehlings MG. Editorial: recommendations regarding the use of methylprednisolone in acute spinal cord injury: making sense out of the controversy. Spine 26[Suppl 24):56-57, 2001.

99. Otani K, Abe H, Kadoya S. Beneficial effect of methylprednisolone sodium succinate in the treatment of acute spinal cord injury (in Japanese). Sekitsui Sekizui 7:633-647, 1994.

100. Petitjean ME, Pointillart V, Dixmerias F. Medical treatment of spinal cord injury in the acute stage (in French). Ann Fr Anesth Reanim 17:114-122, 1998.

101. Hurlbert RJ. Methyprednisolone for acute spinal cord injury: reevaluating the NASCIS trials. J Spinal Cord Med 25:206, 2002.

102. Constantini S, Young W. The effects of methylprednisolone and 
the ganglioside GM1 on acute spinal cord injury in rats. $J$ Neurosurg 80:97-111, 1994.

103. Bao F, Liu D. Peroxynitrite generated in the rat spinal cord induces apoptotic cell death and activates caspase-3. Neuroscience 116:59-70, 2003.

104. Xu J, Gyeong-Moon K, Chen S, Yan P, Hinan A, Ku G et al. iNOS and nitrotyrosine expression after spinal cord injury. $J$ Neurotrauma 18:523-532, 2001.

105. Beckman JS. The double-edged role of nitric oxide in brain function and superoxide-mediated injury. J Dev Physiol 15:5359, 1991.

106. Radi R, Beckman JS, Bush KM, Freeman BA. Peroxynitriteinduced membrane lipid peroxidation: the cytotoxic potential of superoxide and nitric oxide. Arch Biochem Biophys 288:481487, 1991.

107. Carroll RT, Galatsis P, Borosky S, Kopec KK, Kumar V, Althaus JS et al. 4-Hydroxy-2,2,6,6-tetramethylpiperidine-1-oxyl (Tempol) inhibits peroxynitrite-mediated phenol nitration. Chem Res Toxicol 13:294-300, 2000.

108. Hall ED, Kupina NC, Althaus JS. Peroxynitrite scavengers for the acute treatment of traumatic brain injury. Ann NY Acad Sci 890: 462-468, 1999.

109. Chabrier PE, Auguet M, Spinnewyn B, Auvin S, Cornet S, Demerle-Pallardy C et al. BN 80933, a dual inhibitor of neuronal nitric oxide synthase and lipid peroxidation: a promising neuroprotective strategy. Proc Natl Acad Sci USA 96:10824-10829, 1999.

110. Tonai T, Taketani Y, Ohmoto Y, Ueda N, Nishisho T, Yamamoto S. Cyclooxygenase-2 induction in rat spinal cord injury mediated by proinflammatory tumor necrosis factor-alpha and interleukin-1. Adv Exp Med Biol 507:397-401, 2002.

111. Schwab JM, Brechtel K, Nguyen TD, Schluesener HJ. Persistent accumulation of cyclooxygenase-1 (COX-1) expressing microglia/macrophages and upregulation by endothelium following spinal cord injury. J Neuroimmunol 111:122-130, 2000.

112. Resnick DK, Graham SH, Dixon CE, Marion DW. Role of cyclooxygenase 2 in acute spinal cord injury. J Neurotrauma 15: 1005-1013, 1998.

113. Hoffmann C. COX-2 in brain and spinal cord implications for therapeutic use. Curr Med Chem 7:1113-1120, 2000.

114. Hains BC, Yucra JA, Hulsebosch CE. Reduction of pathological and behavioral deficits following spinal cord contusion injury with the selective cyclooxygenase-2 inhibitor NS-398. J Neurotrauma 18:409-423, 2001.

115. Yuen PW, Wang KKW. Therapeutic potential of calpain inhibitors in neurodegenerative disorder. Expert Opin Investig Drugs 5:1291-1304, 1996.

116. Yuen P, Wang KW. Calpain inhibitors: novel neuroprotectants and potential anticataract agents. Drugs Future 23:741-749, 1998.

117. Wingrave JM, Schaecher KE, Sribnick EA, Wilford GG, Ray SK, Hazen-Martin DJ et al. Early induction of secondary injury factors causing activation of calpain and mitochondria-mediated neuronal apoptosis following spinal cord injury in rats. $J$ Neurosci Res 73:95-104, 2003.

118. Ray SK, Hogan EL, Banik NL. Calpain in the pathophysiology of spinal cord injury: neuroprotection with calpain inhibitors. Brain Res Rev 42:169-185, 2003.

119. Ray SK, Matzelle DD, Wilford GG, Hogan EL, Banik NL. Inhibition of calpain-mediated apoptosis by E-64 d-reduced immediate early gene (IEG) expression and reactive astrogliosis in the lesion and penumbra following spinal cord injury in rats. Brain Res Rev 916:115-126, 2001.

120. Ray SK, Matzelle DD, Wilford GG, Hogan EL, Banik NL. Cell death in spinal cord injury (SCI) requires de novo protein synthesis: calpain inhibitor E-64-d provides neuroprotection in SCI lesion and penumbra. Ann NY Acad Sci 939:436-449, 2001.

121. Ray SK, Matzelle DD, Wilford GG, Hogan EL, Banik NL. Increased calpain expression is associated with apoptosis in rat spinal cord injury: calpain inhibitor provides neuroprotection. Neurochem Res 25:1191-1198, 2000.

122. Shields DC, Schaecher KE, Hogan EL, Banik NL. Calpain activity and expression increased in activated glial and inflamma- tory cells in penumbra of spinal cord injury lesion. J Neurosci Res 61:146-150, 2000.

123. Banik NL, Shields DC. The role of calpain in neurofilament protein degradation associated with spinal cord injury. Methods Mol Biol 144:195-201, 2000.

124. Zhang SX, Bondada V, Geddes JW. Evaluation of conditions for calpain inhibition in the rat spinal cord: effective postinjury inhibition with intraspinal MDL28170 microinjection. $J$ Neurotrauma 20:59-67, 2003.

125. Faden AI, Jacobs TP, Holaday JW. Thyrotropin-releasing hormone improves neurologic recovery after spinal trauma in cats. N Engl J Med 305:1063-1067, 1981.

126. Faden AI, Sacksen I, Noble LJ. Structure-activity relationships of TRH analogs in rat spinal cord injury. Brain Res 448:287-293, 1988.

127. Pitts LH, Ross A, Chase GA, Faden AI. Treatment with thyrotropin-releasing hormone (TRH) in patients with traumatic spinal cord injuries. J Neurotrauma 12:235-243, 1995.

128. Faden AI. TRH analog YM-14673 improves outcome following traumatic brain and spinal cord injury in rats: dose-response studies. Brain Res 486:228-235, 1989.

129. Faden AI, Fox G, Fan L, Knoblach S, Araldi GL, Kozikowski AP. Neuroprotective and cognitive enhancing effects of novel small peptides. Ann NY Acad Sci 890:120, 1999.

130. Beattie MS, Farooqui AA, Bresnahan JC. Rew of current evidence for apoptosis after spinal cord injury. $J$ Neurotrauma 17 915-925, 2000.

131. Crowe MJ, Bresnahan JC, Shuman SL, Masters JN, Beattie MS. Apoptosis and delayed degeneration after spinal cord injury in rats and monkeys. Nat Med 3:73-76, 1997.

132. Emery E, Aldana P, Bunge MB, Puckett W, Srinivasan A, Keane RW et al. Apoptosis after traumatic human spinal cord injury. J Neurosurg 89:911-920, 1998.

133. Liu XZ, Xu XM, Hu R, Du C, Zhang SX, McDonald JW et al. Neuronal and glial apoptosis after traumatic spinal cord injury. J Neurosci 17:5395-5406, 1997.

134. Lou J, Lenke LG, Ludwig FJ, O'Brien MF. Apoptosis as a mechanism of neuronal cell death following acute experimental spinal cord injury. Spinal Cord 36:683-690, 1998.

135. Shuman SL, Bresnahan JC, Beattie MS. Apoptosis of microglia and oligodendrocytes after spinal cord contusion in rats. $J \mathrm{Neu}$ rosci Res 50:798-808, 1997.

136. Takagi T, Takayasu M, Mizuno M, Yoshimoto M, Yoshida J. Caspase activation in neuronal and glial apoptosis following spinal cord injury in mice. Neurol Med Chir (Tokyo) 43:20-30, 2003.

137. Yong C, Arnold PM, Zoubine MN, Citron BA, Watanabe I, Berman NE et al. Apoptosis in cellular compartments of rat spinal cord after severe contusion injury. J Neurotrauma 15:459-472, 1998.

138. Beattie MS, Hermann GE, Rogers RC, Bresnahan JC. Cell death in models of spinal cord injury. Prog Brain Res 137:37-47, 2002.

139. Citron BA, Arnold PM, Sebastian C, Qin F, Malladi S, Ameenud$\operatorname{din} \mathrm{S}$ et al. Rapid upregulation of caspase-3 in rat spinal cord after injury: mRNA, protein, and cellular localization correlates with apoptotic cell death. Exp Neurol 166:213-226, 2000.

140. Li M, Ona VO, Chen M, Kaul M, Tenneti L, Zhang X et al. Functional role and therapeutic implications of neuronal caspase- 1 and -3 in a mouse model of traumatic spinal cord injury. Neuroscience 99:333-342, 2000.

141. Springer JE, Nottingham SA, McEwen ML, Azbill RD, Jin Y. Caspase-3 apoptotic signaling following injury to the central nervous system. Clin Chem Lab Med 39:299-307, 2001.

142. Springer J, Azbill R, Knapp P. Activation of the caspase-3 apoptotic cascade in traumatic spinal cord injury. Nat Med 5:943946, 1999.

143. Chen J, Nagayama T, Jin K, Stetler RA, Zhu RL, Graham SH et al. Induction of caspase-3-like protease may mediate delayed neuronal death in the hippocampus after transient cerebral ischemia. J Neurosci 18:4914-4928, 1998.

144. Endres M, Namura S, Shimizu-Sasamata M, Waeber C, Zhang L, Gomez-Isla $\mathrm{T}$ et al. Attenuation of delayed neuronal death after 
mild focal ischemia in mice by inhibition of the caspase family. J Cereb Blood Flow Metab 18:238-247, 1998.

145. Hara H, Friedlander RM, Gagliardini V, Ayata C, Fink K, Huang $\mathrm{Z}$ et al. Inhibition of interleukin 1 beta converting enzyme family proteases reduces ischemic and excitotoxic neuronal damage. Proc Natl Acad Sci USA 94:2007-2012, 1997.

146. Ni B, Wu X, Su Y, Smalstig EB, Clemens J, Paul SM et al. Transient global forebrain ischemia induces a prolonged expression of the caspase- 3 mRNA in rat hippocampal CA1 pyramidal neurons. J Cereb Blood Flow Metab 18:248-256, 1998.

147. Pike BR, Zhao X, Newcomb JK, Posmantur RM, Wang KK, Hayes RL. Regional calpain and caspase-3 proteolysis of alphaspectrin after traumatic brain injury. Neuroreport 9:2437-2442, 1998.

148. Yakovlev AG, Knoblach SM, Fan L, Fox GB, Goodnight R, Faden AI. Activation of CPP32-like caspases contributes to neuronal apoptosis and neurological dysfunction after traumatic brain injury. J Neurosci 17:7415-7424, 1997.

149. Clark RS, Kochanek PM, Watkins SC, Chen M, Dixon CE, Seidberg NA et al. Caspase-3 mediated neuronal death after traumatic brain injury in rats. $J$ Neurochem 74:740-753, 2000.

150. Eldadah BA, Faden AI. Caspase pathways, neuronal apoptosis, and CNS injury. J Neurotrauma 17:811-829, 2000.

151. Velier JJ, Ellison JA, Kikly KK, Spera PA, Barone FC, Feuerstein GZ. Caspase- 8 and caspase- 3 are expressed by different populations of cortical neurons undergoing delayed cell death after focal stroke in the rat. $J$ Neurosci 19:5932-5941, 1999.

152. Zhang C, Raghupathi R, Saatman K, LaPlaca M, McIntosh T. Regional and temporal alterations in DNA fragmentation factor (DFF)-like proteins following experimental brain trauma in the rat. J Neurochem 73:1650-1659, 1999.

153. Bossy-Wetzel E, Newmeyer DD, Green DR. Mitochondrial cytochrome c release in apoptosis occurs upstream of DEVD- specific caspase activation and independently of mitochondrial transmembrane depolarization. EMBO J 17:37-49, 1998.

154. Du C, Fang M, Li Y, Li L, Wang X. Smac, a mitochondrial protein that promotes cytochrome c-dependent caspase activation by eliminating IAP inhibition. Cell 102:33-42, 2000.

155. Kluck RM, Martin SJ, Hoffman BM, Zhou JS, Green DR, Newmeyer DD. Cytochrome c activation of CPP32-like proteolysis plays a critical role in a Xenopus cell-free apoptosis system. EMBO J 16:4639-4649, 1997.

156. Liu X, Kim CN, Yang J, Jemmerson R, Wang X. Induction of apoptotic program in cell-free extracts: requirement for dATP and cytochrome c. Cell 86:147-157, 1996.

157. Verhagen AM, Ekert PG, Pakusch M, Silke J, Connolly LM, Reid GE et al. Identification of DIABLO, a mammalian protein that promotes apoptosis by binding to and antagonizing IAP proteins. Cell 102:43-53, 2000.

158. Holcik M, Gibson H, Korneluk RG. XIAP: Apoptotic brake and promising therapeutic target. Apoptosis 6:253-261, 2001.

159. Ekert PG, Silke J, Hawkins CJ, Verhagen AM, Vaux DL. DIABLO promotes apoptosis by removing MIHA/XIAP from processed caspase 9. J Cell Biol 152:483-490, 2001.

160. Srinivasula SM, Hegde R, Saleh A, Datta P, Shiozaki E, Chai J et al. A conserved XIAP-interaction motif in caspase-9 and Smac/ DIABLO regulates caspase activity and apoptosis. Nature 410: 112-116, 2001.

161. Wu G, Chai J, Suber TL et al. Structural basis of IAP recognition by Smac/DIABLO. Nature 408:1008-1012, 2000.

162. Chai J, Du C, Wu JW, Kyin S, Wang X, Shi Y. Structural and biochemical basis of apoptotic activation by Smac/DIABLO. $\mathrm{Na}$ ture 406:855-862, 2000.

163. Parrish J, Li L, Klotz K, Ledwich D, Wang X, Xue D. Mitochondrial endonuclease $\mathrm{G}$ is important for apoptosis in C. elegans. Nature 412:90-94, 2001.

164. Li LY, Luo X, Wang X. Endonuclease G is an apoptotic DNase when released from mitochondria. Nature 412:95-99, 2001.

165. Cande C, Cohen I, Daugas E, Ravagnan L, Larochette M, Zamzami $\mathrm{N}$ et al. Apoptosis-inducing factor (AIF): a novel caspase-independent death effector released from mitochondria. Biochimie 84:215-222, 2002.
166. Lorenzo HK, Susin SA, Penninger J, Kroemer G. Apoptosis inducing factor (AIF): a phylogenetically old, caspase-independent effector of cell death. Cell Death Differ 6:516-524, 1999.

167. Daugas E, Nochy D, Ravagnan L, Loeffler M, Susin SA, Zamzami $\mathrm{N}$ et al. Apoptosis-inducing factor (AIF): a ubiquitous mitochondrial oxidoreductase involved in apoptosis. FEBS Lett 476:118-123, 2000.

168. Ozawa H, Keane RW, Marcillo AE, Diaz PH, Dietrich WD. Therapeutic strategies targeting caspase inhibition following spinal cord injury in rats. Exp Neurol 177:306-313, 2002.

169. Datta SR, Dudek H, Tao X, Masters S, Fu H, Gotoh Y et al. Akt phosphorylation of BAD couples survival signals to the cellintrinsic death machinery. Cell 91:231-241, 1997.

170. Dudek H, Datta SR, Franke TF, Birnbaum MJ, Yao R, Cooper $\mathrm{GM}$ et al. Regulation of neuronal survival by the serine-threonine protein kinase Akt. Science 275:661-665, 1997.

171. Flores AI, Mallon BS, Matsui T, Ogawa W, Rosenzweig A, Okamoto $\mathrm{T}$ et al. Akt-mediated survival of oligodendrocytes induced by neuregulins. J Neurosci 20:7622-7630, 2000.

172. Goswami R, Kilkus J, Dawson SA, Dawson G. Overexpression of akt (protein kinase B) confers protection against apoptosis and prevents formation of ceramide in response to pro-apoptotic stimuli. J Neurosci Res 57:884-893, 1999.

173. Kennedy SG, Kandel ES, Cross TK, Hay N. Akt/Protein kinase B inhibits cell death by preventing the release of cytochrome $\mathrm{c}$ from mitochondria. Mol Cell Biol 19:5800-5810, 1999.

174. Nunez G, del Peso L. Linking extracellular survival signals and the apoptotic machinery. Curr Opin Neurobiol 8:613-618, 1998.

175. Chen RH, Su YH, Chuang RL, Chang TY. Suppression of transforming growth factor-beta-induced apoptosis through a phosphatidylinositol 3-kinase/Akt-dependent pathway. Oncogene 17:1959-1968, 1998.

176. Crowder RJ, Freeman RS. Phosphatidylinositol 3-kinase and Akt protein kinase are necessary and sufficient for the survival of nerve growth factor-dependent sympathetic neurons. J Neurosci 18:2933-2943, 1998.

177. Eves EM, Xiong W, Bellacosa A, Kennedy SG, Tsichlis PN, Rosner MR et al. Akt, a target of phosphatidylinositol 3-kinase, inhibits apoptosis in a differentiating neuronal cell line. Mol Cell Biol 18:2143-2152, 1998.

178. Kermer P, Klocker N, Labes M, Bahr M. Insulin-like growth factor-I protects axotomized rat retinal ganglion cells from secondary death via PI3-K-dependent Akt phosphorylation and inhibition of caspase-3 in vivo. J Neurosci 20:2-8, 2000.

179. Yao R, Cooper GM. Requirement for phosphatidylinositol-3 kinase in the prevention of apoptosis by nerve growth factor. Science 267:2003-2006, 1995.

180. Duckett CS, Li F, Wang Y, Tomaselli KJ, Thompson CB, Armstrong RC. Human IAP-like protein regulates programmed cell death downstream of Bcl-xL and cytochrome c. Mol Cell Biol 18:608-615, 1998

181. Deveraux QL, Roy N, Stennicke HR, Van Arsdale T, Zhou Q, Srinivasula SM et al. IAPs block apoptotic events induced by caspase- 8 and cytochrome $\mathrm{c}$ by direct inhibition of distinct caspases. EMBO J 17:2215-2223, 1998

182. Ekert PG, Silke J, Vaux DL. Inhibition of apoptosis and clonogenic survival of cells expressing crmA variants: optimal caspase substrates are not necessarily optimal inhibitors. EMBO $J 18$ : 330-338, 1999.

183. Salvesen GS, Duckett CS. IAP proteins: blocking the road to death's door. Nat Rev Mol Cell Biol 3:401-410, 2002.

184. Hay BA, Wassarman DA, Rubin GM. Drosophila homologs of baculovirus inhibitor of apoptosis proteins function to block cell death. Cell 83:1253-1262, 1995.

185. Hay BA. Understanding IAP function and regulation: a view from Drosophila. Cell Death Differ 7:1045-1056, 2000.

186. Head MS, Ryan MD, Lee D, Feng Y, Janson CA, Concha NA et al. Structure-based combinatorial library design: discovery of non-peptidic inhibitors of caspases 3 and 8. J Comput Aided Mol Des 15:1105-1117, 2001. 